\title{
Neuronal Glutamatergic Network Electrically Wired with Silent But Activatable Gap Junctions
}

\author{
Diana J. Ixmatlahua, ${ }^{1}$ Bianca Vizcarra, ${ }^{1}$ Gisela Gómez-Lira, ${ }^{1}$ Isabel Romero-Maldonado, ${ }^{1}$ Franco Ortiz, ${ }^{1}$ \\ Gerardo Rojas-Piloni, ${ }^{2}$ and Rafael Gutiérrez ${ }^{1}$ \\ ${ }^{1}$ Departamento de Farmacobiología, Centro de Investigación y de Estudios Avanzados del Instituto Politécnico Nacional, 14330 Mexico City, \\ Mexico, and ${ }^{2}$ Departamento de Neurobiología del Desarrollo y Neurofisiología, Instituto de Neurobiología, Campus UNAM-Juriquilla, Universidad \\ Nacional Autónoma de México, 76230 Querétaro, Mexico
}

It is widely assumed that electrical synapses in the mammalian brain, especially between interneurons, underlie neuronal synchrony. In the hippocampus, principal cells also establish electrical synapses with each other and have also been implicated in network oscillations, whereby the origin of fast electrical activity has been attributed to ectopic spikelets and dendro-dendritic or axo-axonal gap junctions. However, if electrical synapses were in axo-dendritic connections, where chemical synapses occur, the synaptic events would be mixed, having an electrical component preceding the chemical one. This type of communication is less well studied, mainly because it is not easily detected. Moreover, a possible scenario could be that an electrical synapse coexisted with a chemical one, but in a nonconductive state; hence, it would be considered inexistent. Could chemical synapses have a quiescent electrical component? If so, can silent electrical synapses be activated to be detected? We addressed this possibility, and we here report that, indeed, the connexin-36-containing glutamatergic mossy fiber synapses of the rat hippocampus express previously unrecognized electrical synapses, which are normally silent. We reveal that these synapses are $\mathrm{pH}$ sensitive, actuate in vitro and in vivo, and that the electrical signaling is bidirectional. With the simultaneous recording of hundreds of cells, we could reveal the existence of an electrical circuit in the hippocampus of adult rats of either sex consisting of principal cells where the nodes are interregional glutamatergic synapses containing silent but ready-to-use gap junctions.

Key words: electrical circuit; electrical synapses; gap junctions; hippocampus; mixed synapses; mossy fibers

Significance Statement

In this work, we present a series of experiments, both in vitro and in vivo, that reveal previously unrecognized silent $\mathrm{pH}$-sensitive electrical synapses coexisting in one of the best studied glutamatergic synapses of the brain, the mossy fiber synapse of the hippocampus. This type of connectivity underlies an "electrical circuit" between two substructures of the adult rat hippocampus consisting of principal cells where the nodes are glutamatergic synapses containing silent but ready-to-use gap junctions. Its identification will allow us to explore the participation of such a circuit in physiological and pathophysiological functions and will provide valuable conceptual tools to understanding computational and regulatory mechanisms that may underlie network activity.

Received Oct. 31, 2019; revised May 2, 2020; accepted May 5, 2020.

Author contributions: R.G. designed research; D.J.I., B.V., G.G.-L., I.R.-M., F.O., G.R.-P., and R.G. performed research; D.J.I., B.V., G.G.-L., I.R.-M., and R.G. analyzed data; R.G. wrote the paper.

The authors declare no competing financial interests.

This work was supported by Grants (B-254339 and IFC-2016/1600 from Consejo Nacional de Ciencia y Tecnología (CONACYT); from Fundación Miguel Alemán; and from IBM to R.G., D.J.I., B.V., I.R.-M, and F.O. were supported by scholarships from CONACYT. G.R.-P. was supported by Universidad Nacional Autónoma de México, PAPIIT-DGAPA Grant IN201518, and Grant IFC-846 from CONACYT. Part of the data in this work is in partial fulfillment of the doctoral dissertation of D.J.I. We thank Kai Kaila, Juan Lerma, Roger Traub, and Andreas Draguhn for stimulating discussions during the execution of the research; and Isabel Sollozo for advice on statistics.

Correspondence should be addressed to Rafael Gutiérrez at rafagut@cinvestav.mx.

https://doi.org/10.1523/JNEUROSCI.2590-19.2020

Copyright $\odot 2020$ the authors

\section{Introduction}

It is widely assumed that electrical synapses in the adult rodent hippocampus, especially between interneurons, underlie neuronal synchrony. Principal cells, however, can also establish dendro-dendritic and axo-axonic synapses containing gap junctions (MacVicar and Dudek, 1981; Valiante et al., 1995; Gibson et al., 1999; Galarreta and Hestrin, 2001; Schmitz et al., 2001; HamzeiSichani et al., 2007) that have been implicated in network oscillations (Traub et al., 2017). The occurrence of electric spikelets in hippocampal pyramidal cells has been related to ectopic, dendritic, or axonal spikes as well as to distal electrical communication (Spencer and Kandel, 1961); indeed, electrical coupling between axons or dendrites of principal cells and between interneurons 
has been corroborated with paired recordings (MacVicar and Dudek, 1981; Galarreta and Hestrin, 2001). However, the presence and role of axo-dendritic, mixed, electrical-chemical transmission between principal cells in the mammalian telencephalon is less well studied, mainly because of the lack of their anatomic and physiological detection (for review, see Traub et al., 2018). An axodendritic mixed, electrical-chemical synapse has been described between two principal cells of the hippocampus, the granule cells (GCs), through their mossy fibers (MFs), and dendrites of CA3 pyramidal cells of adult rats (Vivar et al., 2012). Dye-coupling experiments as well as ultrastructural studies supported the functional data by showing the presence of Connexin36 (Cx36) colocalizing with glutamate receptors in axo-dendritic contacts (HamzeiSichani et al., 2012). Interestingly, while abundant expression of Cx36 protein in MF giant boutons has been described in the adult rat (Nagy, 2012), electrophysiological recordings in hippocampal slices showed a very low probability (7\%) of finding pyramidal cells responding with mixed electrical-chemical excitatory postsynaptic potentials on MF stimulation (Vivar et al., 2012). The following four explanations may account for this low probability: (1) gap junctions exist in a little subset of synapses in the adult hippocampus, so finding mixed responses directly depends on the sampling conditions (Vivar et al., 2012); (2) gap junctions exist in many MF boutons, but preparing slices prunes most of the dendritic and axonal arborizations, leaving few connections in the slice to be detected (Hamzei-Sichani et al., 2012); (3) Cx36 may be abundant, but its immunodetection could consist mainly of hemichannels on either the presynaptic or the postsynaptic site (Belousov and Fontes, 2013), failing to form channels; and, finally, (4) there are indeed many mixed synapses, but only a few can be detected because most of these connections are in a closed, nonconductive state. If so, how can one detect quiescent electrical synapses? Can they be opened? How?

Using cocultures of identified granule and pyramidal cells (Osorio et al., 2013), acute brain slices, and in vivo, we here demonstrate the broad existence of previously unrecognized electrical synapses in the Connexin-36-containing glutamatergic MF synapse of the hippocampus, which are normally silent. While the MF synapse normally uses glutamate for fast neurotransmission, electrical signaling is normally turned off, but it can be switched on to a conductive state. With the simultaneous recording of hundreds of cells, we could reveal the existence of an electrical circuit in the adult rat hippocampus consisting of principal cells where the nodes are interregional glutamatergic synapses containing silent but ready-to-use gap junctions.

\section{Materials and Methods}

The Ethics Committee for Animal Research of our institutions approved all experimental procedures, which were performed in adherence with the National Institutes of Health Guide for the Care and Use of Laboratory Animals (eighth edition).

Cocultures of $\mathrm{GFP}^{+}$granule cells with $G F P^{-}$pyramidal cells and interneurons of $C A 3$. We used the culture method previously reported (Osorio et al., 2013), consisting of dissociation and seeding of granule cells obtained from $\mathrm{GFP}^{+}$-expressing Sprague Dawley rats together with pyramidal cells and interneurons of CA3 obtained from wild-type Sprague Dawley rats $2 \mathrm{~d}$ after birth. We incubated the dissected tissue in papain for enzymatic cleavage $(1 \mathrm{mg} / \mathrm{ml}$; Worthington) for $10 \mathrm{~min}$, washed with cold HBSS, and, finally, cells were separated by mechanical dissociation using a plastic pipette tip; the solution was filtered through a $40 \mu \mathrm{m}$ grid. Next, the cells in suspension were seeded in coverslips with Matrigel (catalog \#356234, BD Biosciences) and placed in a Petri dish. After allowing them to settle down for $3 \mathrm{~h}$ in an incubator (95\% air, 5\%
$\mathrm{CO}_{2}, 37^{\circ} \mathrm{C}$ ), we added $2 \mathrm{ml}$ of culture medium [Eagle's minimal essential medium; human transferrin, $100 \mu \mathrm{m} / \mathrm{ml}$; insulin, $25 \mu \mathrm{m} / \mathrm{ml}$; GlutaMAX, $2 \mathrm{~mm}$; and fetal bovine serum (FBS), 10\%]. After $24 \mathrm{~h}$ in culture, the medium was substituted with medium enriched with 5\% FBS (supplemented with $2 \%$ B27 medium and $4 \mu \mathrm{M}$ cytosine-p-arabinofuranoside). The cultures were used for recording after $21 \mathrm{~d}$ of incubation.

Detection of Cx36 by immunofluorescence. For immunodetection of Cx36 in the cultured cells, we fixed the hippocampal cultures in $4 \%$ paraformaldehyde (PFA) for $10 \mathrm{~min}$, after rising $3 \times$, the cultures were treated with PBS with $5 \%$ BSA and $0.3 \%$ Triton X-100 over $2 \mathrm{~h}$ at room temperature. Next, they were incubated all night with the primary antibody to Cx36 (1:100; catalog \#36-4600, Thermo Fisher Scientific) in PBS with 5\% BSA at room temperature. After rinsing, the cultures were incubated with the following secondary antibody: Alexa Fluor 568 anti-rabbit (1:500; catalog \#A10042, Molecular Probes) for $2 \mathrm{~h}$. Negative controls were performed by the omission of primary antibody and resulted in the absence of immunofluorescence.

The cultures were mounted in Vectashield Vibrance mounting medium with DAPI (catalog \#H-1800, Vector Laboratories) and examined on a confocal microscope (model LSM 800, Zeiss; see below).

Electrophysiology in cultured cells. The cultures, in coverslips containing $5840 \pm 1603 \mathrm{cells} / \mathrm{cm}^{2}$, were placed in a recording chamber under the microscope with epifluorescence capabilities (Eclipse E600FN, Nikon). The cells were visualized using $10 \times$ and $40 \times$ objectives (excitation, $450-490 \mathrm{~nm}$; long-pass barrier filter, $515 \mathrm{~nm}$ for $\mathrm{GFP}^{+}$detection). The cultures were continuously perfused at $1.5 \mathrm{ml} / \mathrm{min}$ with artificial CSF (ACSF) at room temperature $\left(22^{\circ} \mathrm{C}\right)$. The ACSF contained the following (in mM): $150 \mathrm{NaCl}, 3 \mathrm{KCl}, 1.8 \mathrm{MgSO}_{4}, 2 \mathrm{CaCl}_{2}, 1.25 \mathrm{Na}_{2} \mathrm{PO}_{4}, 26$ $\mathrm{NaHCO}_{3}$, and 10 glucose, $\mathrm{pH}$ adjusted to 7.4 and balanced with $95 \% \mathrm{O}_{2^{-}}$ $5 \% \mathrm{CO}_{2}$. Recordings were performed with the patch-clamp technique in whole-cell mode. We used borosilicate pipettes of 4-6 M $\Omega$ filled with a solution consisting of the following $(\mathrm{mM}): 120 \mathrm{~K}$-gluconate, $20 \mathrm{KCl}, 10$ HEPES, 0.5 EGTA, 0.5 Na-GTP, 2 Na-ATP, and 10 phosphocreatine, $\mathrm{pH}$ 7.2. Additionally, the pipette of the presynaptic granule cell contained Alexa Fluor 594 (25 $\mu \mathrm{M}$; Thermo Fisher Scientific) to label the axon and thus select a likely postsynaptic target cell in its vicinity. Recorded signals were amplified (Multiclamp 700B Amplifier, Molecular Devices), digitized at $25 \mathrm{kHz}$, and filtered at $2 \mathrm{kHz}$ (Digidata $1440 \mathrm{~A}$, Molecular Devices), and stored in a personal computer. We analyzed the signals with the pClamp10 program (Molecular Devices). The latency of synaptic events was considered as the time interval between the peak of the presynaptic action potential and the beginning of the synaptic event.

Slice preparation and electrophysiology. Male Wistar rats $(25 \mathrm{~d}$ old $)$ were deeply anesthetized (pentobarbital, $50 \mathrm{mg} / \mathrm{kg}$, i.p.), brains were rapidly removed, and transverse entorhinal cortex-hippocampal slices of $400 \mu \mathrm{m}$ were obtained with a Vibroslicer (model VT1200, Leica). Slices were next submerged in oxygenated ACSF at $35^{\circ} \mathrm{C}$ for $1 \mathrm{~h}$ before the recordings started. The ACSF contained the following (in $\mathrm{mm}$ ): $\mathrm{NaCl}$ $124, \mathrm{KCl} 3, \mathrm{NaH}_{2} \mathrm{PO}_{4} 1.25, \mathrm{MgCl}_{2} 2, \mathrm{CaCl}_{2} 2, \mathrm{NaHCO}_{3} 26$, and glucose 10 , $\mathrm{pH} 7.35$.

An hour after incubation in normal ACSF, intracellular recordings of pyramidal cells of CA3a-b area were conducted using borosilicate microelectrodes (70-90 M $\Omega$; Brown-Flaming Micropipette Puller) filled with $2 \mathrm{M} \mathrm{K}$-acetate (K-Ac) with or without trimethylamine (TMA) and neurobiotin $0.5 \%$ (as indicated in Results) and an AxoClamp 2B Amplifier (Molecular Devices). The signals were digitized (at $10 \mathrm{kHz}$; Digidata, Molecular Devices) and stored in a hard drive of a personal computer using the pClamp 9 Software (Molecular Devices). The signals were then exported and analyzed offline with the same program. Synaptic responses were evoked by electrical stimulation $(0.1 \mathrm{~ms}$ pulses $)$ provided with bipolar glass-insulated platinum wire $(50 \mu \mathrm{m})$ electrodes over the granular or molecular layer of the DG at threshold intensity that elicited a synaptic response. We usually stimulated several locations in the granular or molecular layer of the DG (5-10) to try to obtain electrical synaptic responses. If no spikelet was observed, we impaled another cell and followed the same protocol until a successful recording occurred. When we analyzed the effects of TMA added to the pipette solution, we first recorded a given pyramidal cell in which synaptic responses were evoked, then blocked by ionotropic glutamate receptors (iGluR) blockers 
and waited for TMA to have an effect, usually after 30-40 min of recording. In some recordings, we waited to observe the combined electricalchemical synaptic response and later blocked the chemical component.

Pharmacological manipulations. We used extracellular (10 mM) and intracellular $(50$ and $200 \mu \mathrm{M}) \mathrm{TMA}, \mathrm{NH}_{4} \mathrm{Cl} 5 \mathrm{~mm}$, and acidic ACSF, $\mathrm{pH}$ 6.85. The drugs used to block chemical neurotransmission were diluted at the desired concentration in the ACSF, namely, NBQX 10 $\mu \mathrm{M}$ (Tocris Bioscience), a blocker of AMPA-kainate glutamate receptor; APV $30 \mu \mathrm{M}$ (Tocris Bioscience), the blocker of NMDA glutamate receptor; and bicuculline (20 $\mu \mathrm{M}$; Sigma-Aldrich), a $\mathrm{GABA}_{\mathrm{A}}$ receptor blocker. To block the electrical neurotransmission, we used mefloquine ( $3 \mu \mathrm{m}$; SigmaAldrich), a selective blocker of Cx36. The group II mGluR agonist $\left(2 \mathrm{~S}, 2^{\prime} \mathrm{R}, 3^{\prime} \mathrm{R}\right)-2-\left(2^{\prime}, 3^{\prime}\right.$-dicarboxycyclopropyl) glycine (DCG-IV; $1-2 \mu \mathrm{M}$; Tocris Bioscience) DCG-IV was used to verify the origin of the synaptic responses, as the activation of these receptors selectively depresses neurotransmitter output from granule cells. As a control for osmolarity changes, we used tetramethylammonium $10 \mathrm{~mm}$ diluted in ACSF, and 50 and 200 $\mu \mathrm{M}$ diluted in the intracellular solution. Neither of these treatments produced changes in synaptic activity.

Electrophysiological recordings in vivo. We conducted electrophysiological experiments in 10 male Wistar rats (280-300 g) under urethane anesthesia ( $1.4 \mathrm{~g} / \mathrm{kg}$, i.p.). A cannula was inserted into the trachea to provide artificial ventilation. End-tidal $\mathrm{CO}_{2}$ concentration was continually measured by means of a capnograph monitor (model VT90041, SurgiVet), and tidal air volume was adjusted to have a stable $\mathrm{CO}_{2}$ concentration of $4.5 \%$. The electrocardiogram was monitored during the experiment, and the core temperature was kept at $37^{\circ} \mathrm{C}$ by means of a heating pad. During the experiment, the depth of the anesthesia was evaluated by tail and toe pinch reflexes. In case of an observed reflex, an additional dose of $10 \%$ of the initial dose of urethane was administered to assure the acceptable depth of anesthesia. The rats were fixed in a stereotaxic apparatus (model SR-6R, Narishige). A cranial window with a size of $1 \times 1 \mathrm{~mm}$ was made $5 \mathrm{~mm}$ posterior to the bregma and $4 \mathrm{~mm}$ lateral on the right cerebral hemisphere above ventral hippocampus (depth, 4500-6000 $\mu \mathrm{m}$; Paxinos and Watson, 1997). Intracellular recordings of pyramidal cells were performed with sharp glass micropipettes filled with $2 \mathrm{M} \mathrm{K}$-acetate, TMA $100 \mathrm{~mm}$, and neurobiotin 0.5\% (50-70 M $\Omega$ ). The pipette was advanced in $2 \mu \mathrm{m}$ steps to locate and impale pyramidal cells of CA3. Spontaneous intracellular activity was recorded for at least $30 \mathrm{~min}$. Following the recording, we provided low-intensity square pulses of positive current through the recording electrode to label the cell with neurobiotin $(<7 \mathrm{nA}$, during $5 \mathrm{~min})$.

Cell reconstructions and dye coupling (in vitro and in vivo). For dyecoupling analysis in the cultured cells, the pipette used to record granule cells contained neurobiotin $0.5 \%$. After recording, they were fixed with PFA $4 \%$ in PBS for $10 \mathrm{~min}$, and washed $3 \times$ for $10 \mathrm{~min}$. They were incubated for $90 \mathrm{~min}$ in a PBS solution with $0.4 \%$ Triton X-100 and were washed $2 \times$ with PBS for $10 \mathrm{~min}$. Subsequently, they were incubated for $2 \mathrm{~h}$ with the Vectastain ABC Kit reagents. To reveal the complex avidinbiotin, the cultures were incubated for $10 \mathrm{~min}$ with diaminobenzidine (DAB Peroxidase Substrate Kit, both from Vector Laboratories). The cultures were finally mounted with the mounting medium Vectashield with DAPI (Vector Laboratories). Microscopic observation and photomicrographs were obtained with an Axio Scope Al Epifluorescence Microscope (Zeiss) and analyzed with the free software ImageJ. For dyecoupling analysis, acute slices were fixed with paraformaldehyde $4 \%$ overnight. After washing $3 \times$ for $10 \mathrm{~min}$ with PBS, $0.1 \mathrm{M}$ and $\mathrm{pH} 7.4$, slices were treated with a blocking solution $(0.4 \%$ Triton X-100 and 5\% BSA in 5\% PBS) for $90 \mathrm{~min}$. The sections were next incubated in the blocking solution with streptavidin, Texas Red (1:500; catalog \#SA-5006, Vector Laboratories) for $2 \mathrm{~h}$. Finally, the slices were washed with PBS and mounted in Vectashield Vibrance Mounting Medium (catalog \#H1800, Vector Laboratories). For dye-coupling analysis of the cells recorded in vivo, the rats were perfused transcardially with phosphate buffer, and brains were removed and fixed with PFA 4\%. The hippocampus was cut in $50-\mu \mathrm{m}$-thick slices for neurobiotin developing, as previously described.

Confocal imaging. An LSM 800 with Airyscan Confocal Microscope (Axio Observer.Z1, Carl Zeiss) with ZEN 2.3 software (Zeiss) was used to acquire the images. Plan-Apochromat $40 \times / 1.3$ Oil diffusion interference contrast (DIC; UV) VIS-IR (visible infrared) M27 and plan-Apochromat $63 \times / 1.40$ Oil DIC M27 objectives were used with the channel Texas Red (450-700 nm) and Alexa Fluor 594 (557-650 $\mathrm{nm}$ ), the pinhole size was set at 1 Airy, and the optical slice thickness was typically $0.6 \mu \mathrm{m}$. From each cell, we took $z$-stack series and reconstructed in $3 \mathrm{D}$ using the Zen 2.3 and Fiji programs. Images were next processed to be observed using augmented reality with the B-Card app for mobile devices (Smartech).

Statistics. Statistical analyses were performed using SigmaPlot (version 12.0; Systat Software). Data are expressed as the mean \pm SEM. The $95 \%$ confidence interval (CI) was used and is expressed in parentheses. Student's $t$ test and ANOVA followed by Holm-Sidak post hoc tests were used to compare the groups. Significance was considered as $p \leq 0.05$. To evaluate the effectiveness with which TMA intracellular solution (TMAi) opened gap junctions, as determined by the presence of fast spikelets, we calculated weighted averages for every experimental condition, namely, four sets (one for every experimenter) of intracellular control recordings (K-Ac in the pipette) and three sets of recordings with different concentrations of TMA dissolved in the recording pipette, with the following formula $X i=\sum X i / \delta x i / \sum \frac{1}{\delta x i}$, where $\delta x i$ represents the square root of the variance $\left(100-\mathrm{SD}^{\star} \mathrm{SD} /\right.$ positive results).

Slice electrophysiology with a microelectrode array of 4096 channels. Slices of $350 \mu \mathrm{m}$ were prepared as previously described (Ortiz et al., 2018). An hour after incubation of the slices in an air-liquid interface perfusing normal ACSF, the slices were transferred to a high-density CMOS (complementary metal-oxide-semiconductor) technology microelectrode array of $64 \times 64$ microelectrodes (BioCam X, 3Brain) and were constantly perfused at $12 \mathrm{ml} / \mathrm{min}$ with oxygenated, standard ACSF at $34 \pm 0.5^{\circ} \mathrm{C}$. Recordings were acquired at a sampling frequency of $17,855.5 \mathrm{~Hz}$ with the program Brain Wave (3Brain) in 3-6 min samples (3Brain) and stored for offline analysis. They were next analyzed with custom programs written using the programming language JuliaLang 1.0.1 (Bezanson et al., 2017) and MATLAB 2018b (MathWorks). After $1 \mathrm{~h}$ of incubation in the microelectrode array, we acquired three samples of $5 \mathrm{~min}$ of spontaneous activity $15 \mathrm{~min}$ apart using control ACSF. We then perfused the slices with the glutamatergic and GABAergic blockers diluted in the bath for $45 \mathrm{~min}$, after which we acquired three samples of $5 \mathrm{~min}$ of activity. Next, we perfused the blockers in an acidic ACSF, pH 6.8, and recorded activity for $5 \mathrm{~min}$, after which physiological ACSF, $\mathrm{pH}$ 7.4, with the blockers was reintroduced. This pulse of acidic ACSF was repeated twice. Finally, mefloquine was added to the acidic ACSF with the blockers and the slices were perfused over $45 \mathrm{~min}$ before three samples of $5 \mathrm{~min}$ each were acquired. A high$\mathrm{K}^{+}(20 \mathrm{~mm})$ solution was perfused after completing the experiment to record high-voltage activity and check for the viability of the preparation (Ortiz et al., 2018).

Active channel detection. On any given time, we monitored and discarded electrodes that were saturated during the recording, and the value was set to that reflecting the average of the baseline before the saturation epoch. A dynamic threshold was set, according to thr $=\sigma * \operatorname{median}(|\mathrm{amp}| / 0.6754)$, where $\sigma=4$ (Quiroga et al., 2004). Channels with suprathreshold activity were eliminated when they showed a Gaussian distribution of the amplitudes of the signals, as this distribution reflects noise and not spiking activity; the latter would yield a non-Gaussian distribution. Once channels that do contain spikes were selected, a reflection of the anatomy of the DG and CA3 can be traced by electrophysiological activity (Ortiz et al., 2018). Spikes were detected following these steps: (1) each signal was filtered by a high-pass filter with cutoff frequencies of $400-8000 \mathrm{~Hz}$, which yields multiunit activity; and (2) the threshold (see above) is again computed from these filtered signals within a $5 \mathrm{~ms}$ window, each computed with $1 \mathrm{~ms}$ displacement. Events above this threshold are thus considered action potentials. We next applied a Wavelet Package Decomposition (WPD) protocol for each detected spike, using a threeorder Coiflet mother wavelet (Hulata et al., 2002). The selected parameters obtained from the WPD were used to apply a modified version of the supraparamagnetic Cluster package (Quiroga et al., 2004) for sorting the spikes into clusters. The clusters detected from each channel were compared with the eight closest neighbors to discard redundancy. The 
spikes, the kinetics of which coincide with those detected in the eight closest neighbors, were used for second local clusterization, thus constituting a virtual channel. The virtual channel is assigned to the place of the electrode with the spike of the greatest amplitude, while neighbor channels "mirroring" the spike are rejected. We next assessed whether spikes detected in all electrodes recording the granular layer of the dentate gyrus triggered spikes in any of all the electrodes recording in the pyramidal cell layer. For this, we triggered the analysis with a spike of each electrode in the dentate and looked for spikes in each of the electrodes recording the CA3 area within a window of 2-6 ms. We confirmed the coactivation of pairs of cells by running Monte Carlo simulations 1000 times with the time stamps of all action potentials of each cell.

\section{Results}

\section{The gap junction opener trimethylamine opens gap junctions in granule cells when applied intracellularly, but not extracellularly}

We first assessed dye coupling, indicative of the presence of open gap junctions, in cocultures of granule and pyramidal cells (Osorio et al., 2013) using neurobiotin (0.5\%) in the recording patch pipette. Two of 27 granule cells presented a single dyecoupled cell (Fig. 1A1) in the presence of the gap junction opener TMA (10 mm; Thomas, 1984; Skeberdis et al., 2011) diluted in the extracellular medium. Surprisingly, when TMA (50 $\mu \mathrm{M})$ was diluted in the intracellular medium (TMAi), it produced extensive dye coupling in 21 of 25 injected granule cells (median, 21 dye-coupled cells; range, 2-59 dye-coupled cells; Fig. 1A2). With single-cell PCR, we confirmed the expression of Cx36 RNA in granule cells (data not shown), but for an analysis of the incidence of Cx36 in the cultured cells, we conducted immunofluorescence experiments to detect the protein. We confirmed that 164 of 185 total cells in four low-density culture plates were immunopositive to $\mathrm{Cx} 36$. Figure $1 B$ shows $\mathrm{GFP}^{+}$granule cells expressing Cx36 along their axons, mostly but not exclusively in giant boutons. Thus, Cx36-containing gap junctions are present in boutons linking granule and pyramidal cell in cultures, which are likely closed but can be opened with TMAi. Therefore, we hypothesized that granule-to-pyramidal cell glutamatergic synapses may constitutively coexpress electrical signaling. Such communication is normally in a silent state, and TMAi opens gap junctions to uncover the electrical component of the synapse. To test this hypothesis, we conducted electrophysiological paired recordings of identified granule and pyramidal cells in control conditions and with TMA diluted in the intracellular solution.

In 20 of 20 pairs recorded under control conditions, action potentials of the granule cells exclusively evoked EPSP in pyramidal cells. The EPSPs had a mean latency of $3.1 \pm 0.2 \mathrm{~ms}(95 \%$ CI, 2.81-3.38), an amplitude of $2.2 \pm 0.2 \mathrm{mV}$ (95\% CI, 1.682.71 ), a $20-80 \%$ rise time of $2.4 \pm 0.1 \mathrm{~ms}$ (95\% CI, 2.37-2.42), a $20-80 \%$ decay time of $7 \pm 0.4 \mathrm{~ms}(95 \% \mathrm{CI}, 6.27-7.72)$, and a failure probability of $0.21 \pm 0.02$ (95\% CI, $0.16-0.25 ; n=14$ pairs; Fig. 1C1,C2). The EPSPs evoked in pyramidal cells were depressed (91.3 $\pm 0.5 \%$; $95 \%$ CI, $90.9-91.69 ; n=8$ pairs) by the activation of type II mGluRs (DCG-IV, $1 \mu \mathrm{M}$; Fig. 1C3) and completely blocked by iGluR antagonists ( $n=20$ pairs). By contrast, in 27 of 30 pairs recorded with TMAi, each action potential of the granule cell evoked in the pyramidal cell a fast spikelet followed by a chemical EPSP (Fig. 1D1,D2) that was depressed by DCG-IV (89.6 $\pm 0.5 \%$; 95\% CI, 87.63-91.57; $n=5$; Fig. 1D3); conversely, action potentials of the pyramidal cell provoked fast spikelets in the presynaptic granule cell (Fig. 2). From the 27 pairs, we obtained the following measurements of the spikelets: latency of $0.9 \pm 0.2 \mathrm{~ms}$ (95\% CI, 0.82-0.98); amplitude of
$1.9 \pm 0.2 \mathrm{mV}$ (95\% CI, $1.79-2.00)$; and $20-80 \%$ rise time of $0.6 \pm 0.1 \mathrm{~ms}$ (95\% CI, 0.54-0.65 ms). The EPSP had an amplitude of $1.9 \pm 0.9 \mathrm{mV}$ (95\% CI, 1.04-2.75) and a $20-80 \%$ decay of $4.4 \pm 0.4 \mathrm{~ms}$ (95\% CI, 3.45-5.34 ms).

The latency and rise time of the EPSP following the spikelet could be not measured as the spikelet modified the kinetics of the onset of the chemical response. Interestingly, fewer EPSP failures were observed when the spikelet was present $[0.12 \pm 0.01$ (95\% CI, $0.10-0.13$; $n=24$ pairs); vs $0.21 \pm 0.02$ (95\% CI, $0.16-$ $0.25 ; n=14$ pairs); Fig. 1D2]. The Cx36-specific gap junction blocker mefloquine (Cruikshank et al., 2004) completely suppressed the spikelets $(n=27$; Fig. 1D3). Thus, in spontaneous activity recorded with TMAi, every action potential fired by either cell provoked an electrical spikelet in the coupled cell; however, when the granule cell fired, each spikelet was followed by an EPSP, whereas retrogradely transmitted spikelets (i.e., from pyramidal cell to granule cell) did not have the chemical component (Fig. 1E1,E2). Figure 2 shows voltage responses in each cell to the injection of current into the complementary cell in the pair, whereby deflections in membrane potential could be seen in both directions. Action potentials of the granule cell evoked spikelets followed by an EPSP in the pyramidal cell, which could be blocked by iGluR antagonists. Conversely, action potentials of the pyramidal cell evoked isolated spikelets in the granule cell that could be blocked by mefloquine $(n=27)$. TMAi has been related to transient acidification of the cell. Therefore, in four pairs where we used TMAi to reveal the mixed electrical-chemical responses, we tested TMA dissolved in the extracellular solution, which is known to alkalinize the cells, and blocked the spikelets in a reversible manner (Fig. 2A). To discard changes in osmolarity as well as to corroborate the specificity of TMA on Cx36 opening, we used another gap junction opener. Tetramethylammonium was applied both extracellularly and intracellularly, at equimolar concentration, without observing any change in the synaptic responses in either case $(n=4)$. Other control experiments included determination of the coupling conductance in either carbonate-based or HEPES-based extracellular solutions ( $n=4$; data not shown), without observing differences in the responses with either $\mathrm{pH}$ buffering solutions.

Because our results are consistent with acidification, and it is known that low $\mathrm{pH}$ opens $\mathrm{Cx} 36$-containing gap junctions (González-Nieto et al., 2008), we recorded granule cell-pyramidal cell pairs exposed to ACSF with decreasing $\mathrm{pH}$ values, from 7.4 to 6.8 in 0.2 steps. Spikelets preceding EPSPs appeared in an all-or-none fashion at $\mathrm{pH} 6.8$, revealing silent electrical synapses in 14 of 14 pairs (Fig. $3 A, B$ ) that could be blocked with mefloquine $(n=14)$. Importantly, the 29 coupled pairs with TMAi synchronized their resting membrane potentials along the experiments, as revealed by cross-correlograms $(0.7 \pm 0.02 ; 95 \%$ CI, 0.49-0.91), whereas 20 control pairs did not $(0.01 \pm 0.001$; 95\% CI, 0.008-0.012; Fig. 3C,D). We next determined the coupling coefficient of the granule cell- pyramidal cell pairs by injecting a current pulse of $-350 \mathrm{pA}$ and a duration of $250 \mathrm{~ms}$ into the "guide" cell, and the voltage deflection was measured in both cells in the stationary state; we repeated the measurements injecting current to the follower cell (Hoge et al., 2011). The coupling coefficient (CC) when the granular cell is the guide cell (G) and the pyramidal cell $(\mathrm{P})$ is the follower cell was as follows: TMA at $50 \mu \mathrm{M}$ : $\mathrm{CC}_{\mathrm{G}-\mathrm{P}}=0.05 \pm 0.02(95 \% \mathrm{CI}, 0.03-0.06 ; n=8)$; TMA at $200 \mu \mathrm{M}: \mathrm{CC}_{\mathrm{G}-\mathrm{P}}=0.07 \pm 0.02$ (95\% CI, 0.05-0.08; $n=17)$. When the pulses were provided to the pyramidal cell, the coupling force was as follows: TMA at $50 \mu \mathrm{M}, \mathrm{CC}_{\mathrm{P}-\mathrm{G}}=$ $0.04 \pm 0.02(95 \%$ CI, $0.03-0.04 ; n=8)$; TMA at $200 \mu \mathrm{M}: \mathrm{CC}_{\mathrm{P}-\mathrm{G}}=$ 
A1

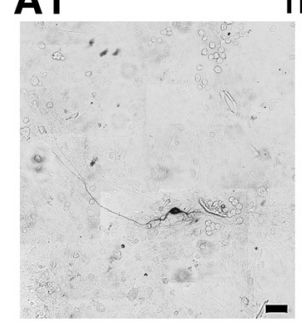

TMAe

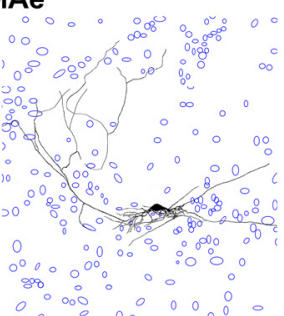

B
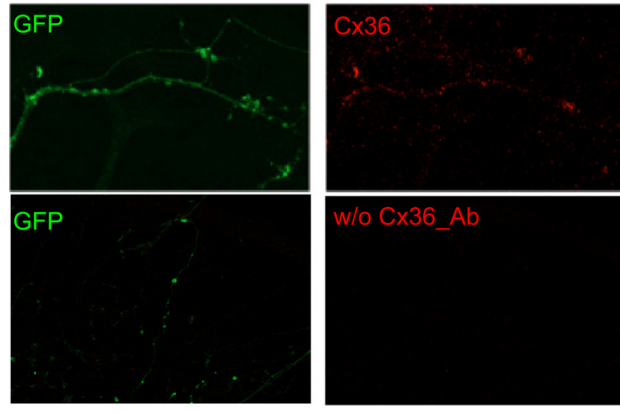

A2

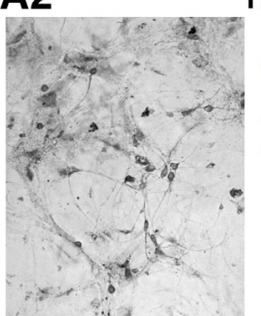

TMAi

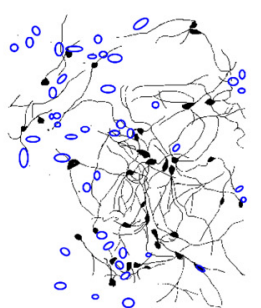

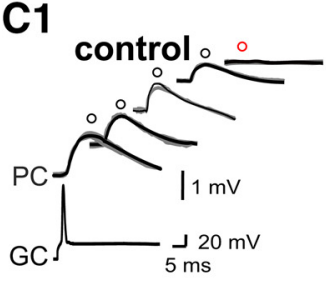

C2

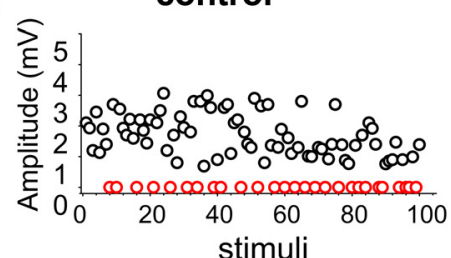

C3
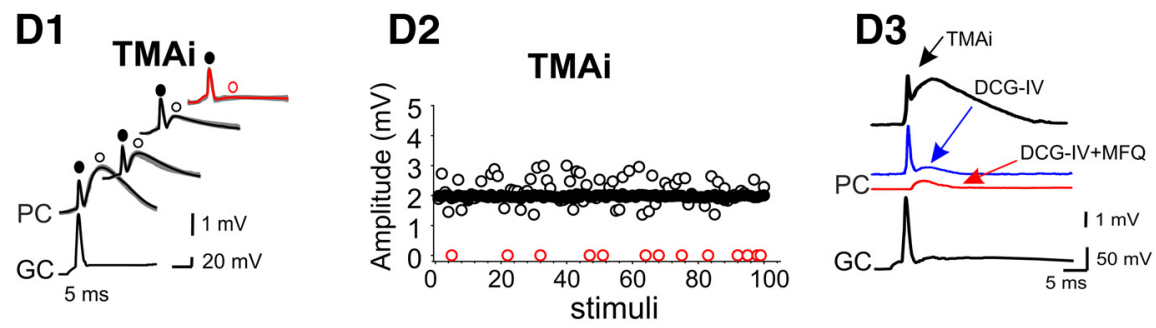

E1

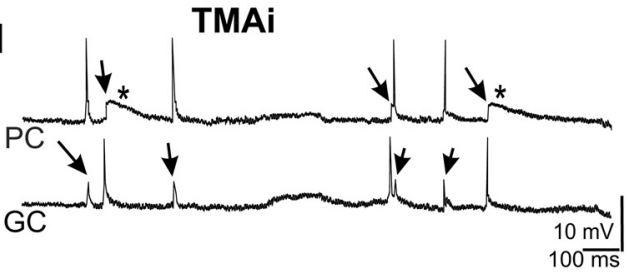

E2

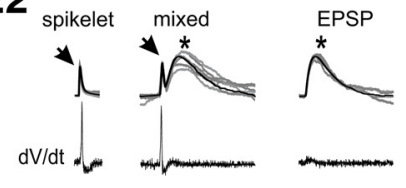

Figure 1. Granule cell-to-pyramidal cell glutamatergic synapses in culture contain silent but activatable electrical connections. A1, Bright-field photomicrograph of a culture plate showing a $\mathrm{GC}$ labeled with neurobiotin. The injection was conducted in the presence of TMA in the perfusion bath (TMAe). Right, Digitalized rendition of the cells in the culture, where cell bodies without label are outlined in blue. Scale bar, $30 \mu \mathrm{m}$. A2, Bright-field photomicrograph showing extensive dye coupling after labeling a single GC with neurobiotin and TMA in the pipette solution (TMAi). Right, Digitalized rendition of the cells in the culture show an interconnected network of granule and pyramidal cells where black cells and processes contain neurobiotin, while nonlabeled cells are outlined in blue. On average, $\sim 20$ cells were dye coupled to each injected, demonstrating that gap junctions are broadly expressed in the cultures $(n=25)$. $\boldsymbol{B}$, Top three images depict immunofluorescence experiments showing that the axons of the $\mathrm{GFP}^{+} \mathrm{GC}$ express $\mathrm{Cx36}$, predominantly, but not exclusively in the giant MF boutons. The bottom three images depict a control experiment, where, in the absence of the primary antibody (Ab), fluorescence in red is absent from the fibers (middle). $\mathbf{C l}_{\text {, In }}$ paired recordings of a GC and a pyramidal cell (PC) with normal intracellular solution, each action potential of a GC regularly evokes an EPSP in the PC (gray traces; black traces represent averaged signals), but some failures occur. C2, The EPSPs were of variable amplitude (white circles) with some failures (red circles). C3, The EPSP was inhibited in the presence of the type II mGluR agonist DCG-IV. Stimuli in these experiments were provided every $5 \mathrm{~s}$. D1, In paired recordings of a GC and a PC, with either of them containing TMA in the intracellular solution, every action potential of a GC evoked a spikelet (black circles) followed by a chemical response (white circles) in the PCs. Gray traces are single responses; black traces represent averaged signals. D2,
$0.05 \pm 0.001(95 \%$ CI, $0.03-0.06 ; n=17$; Fig. $3 E)$. Also, we determined this coefficient during the presynaptic action potential and the postsynaptic spikelet. The action potentials had a mean amplitude of $84.5 \pm 5 \mathrm{mV}$ (95\% CI, 80.6$88.5 \mathrm{mV}$ ), and the spikelets had a mean amplitude of $1.9 \pm 0.2 \mathrm{mV}$ (95\% CI, $1.79-2.00 \mathrm{mV})$, giving a coupling ratio of $0.02 \% \quad(n=270$ action potentials in 27 pairs). The values obtained at different concentrations of TMAi did not show a statistically significant difference (ANOVA, $p>0.05$ ), indicating that its effect is not concentration dependent. Figure $3 F$ summarizes the measurements of the synaptic events in bar graphs with data dispersion.

Silent but ready-to-use electrical synapses in the mossy fibers revealed in acute slices

Are silent electrical synapses also ubiquitous in the MFs in situ? To answer this, we conducted intracellular recordings of pyramidal cells of CA3 from slices of adult Wistar rats. The advantages of microelectrode versus patch clamp for recordings of electrical synapses in the hippocampus have been addressed previously (Vivar et al., 2012). We here take advantage of this method to conclusively prove in a recorded cell the "presence" of the silent electrical

The spikelets had a constant amplitude (black circles) and were evoked by every presynaptic action potential, whereas the chemical component (white circles) was of variable amplitude, and presented failures (red circles). Importantly, however, the failure rate was significantly lower than in the chemical transmission-only condition. D3, The EPSP was inhibited in the presence of the type II mGluR agonist DCG-IV (blue trace), and the spikelet was blocked by the specific $(x 36$ blocker mefloquine (MFG; red trace). E1, In paired recordings of spontaneous activity in the presence of TMAi, every action potential of either cell provoked a spikelet (arrows) in the other cell. Additionally, every action potential of the GC provoked a mixed electrical (arrow)-chemical (asterisk) synaptic event in the PC. E2, Superposition of the different spontaneous synaptic events that can be recorded in $P C$. Gray traces are single responses; black traces represent averaged signals. Isolated spikelets can have their origin in axo-axonic or dendro-dendritic electrical synapses, while axo-dendritic synapses can only provoke isolated spikelets if the current flows from the dendrite to the axon. Mixed electrical-chemical events are originated from axo-dendritic contacts, where glutamate is released and where its receptors and gap junctions coexist. The derivatives below isolate the fast electrical component. Isolated EPSPs are only evoked in control recordings (without TMAi), and their derivative clearly lacks the fast component. 

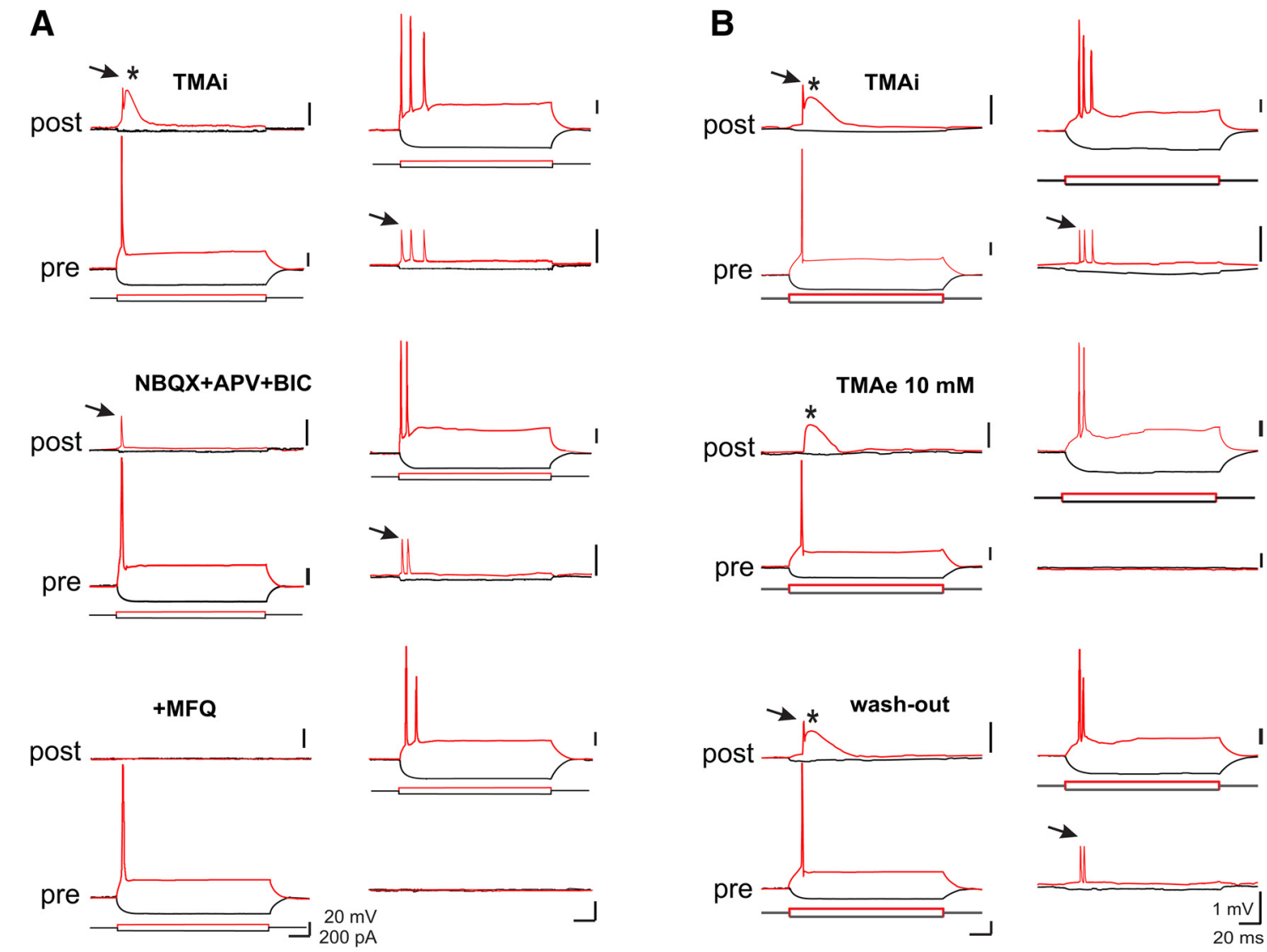

Figure 2. Silent, bidirectional electrical connections are opened by intracellular TMA (TMAi) and closed by extracellular TMA (TMAe). $\boldsymbol{A}$, Paired recordings where depolarizing pulses applied to the GC (pre) triggered action potentials that evoked spikelets (arrows) followed by a glutamatergic EPSP (asterisk) in the pyramidal cell (PC; post). The chemical component could be blocked by iGluR blockers, whereas the electrical component could be blocked by mefloquine (MFQ). Conversely, depolarizing pulses applied to the PC made it fire action potentials. The perfusion of MFQ blocked the depolarizing and hyperpolarizing deflections by the pulse injected into the complementary cell as well as the spikelets. Current steps are indicated below the stimulated cell. Resting membrane potentials (RMPs) were $-69 \mathrm{mV}$ for GC and $-66 \mathrm{mV}$ for PC. B, TMAi $(200 \mu \mathrm{m})$, known to acidify the cell, revealed the electrical component of mixed responses in the PC. The perfusion of TMA (10 mM), which alkalinizes the cells, blocked the depolarizing and hyperpolarizing deflections by the pulse injected to the complementary cell as well as the spikelets in a reversible manner (right-hand traces). Current steps are indicated below the stimulated cell. RMPs were $-72 \mathrm{mV}$ for GC and $-69 \mathrm{mV}$ for PC.

synapse by its delayed opening by our experimental manipulation. Indeed, because sharp microelectrodes may leak their filling solution at a slow rate (Hooper et al., 2015), we hypothesized that recordings with microelectrodes containing TMA would initially show normal glutamatergic transmission and, as TMA leaks into the cells, the activatable electrical synapse would be revealed. Using control $\mathrm{K}^{+}$-acetate in the recording pipette, MF stimulation evoked a monosynaptic, glutamate receptor-mediated EPSP (latency, $3.2 \pm 0.06 \mathrm{~ms} ; 95 \% \mathrm{CI}, 3.09-3.1 ; n=223$ ), while only three responded with a spikelet preceding the EPSP, as previously reported (Vivar et al., 2012). In recordings with microelectrodes containing TMA (100 mM), the spontaneous synaptic activity was not different from that of controls (Fig. 4A1); however, spikelets and spikelets preceding either an EPSP or an action potential appeared after $20-40 \mathrm{~min}$ (Fig. 4A2). The electrical component was clearly identified with the first derivative $(\mathrm{dV} / \mathrm{dt})$ of the trace (Fig. $4 B 1, B 2)$. On the other hand, once obtaining MF-evoked chemical synaptic responses from pyramidal cells, they were completely blocked by iGluR and GABA receptor (GABAR) antagonists (Fig. 4C1,D). In these cells, spikelets could be evoked after 20-40 min of recording with TMAi [Fig. 4D, TMAi $25 \mathrm{~min}, n=3$; Table 1 , where values are expressed as the mean \pm SEM and 95\% CI (in brackets)]. Additionally, hyperpolarization of the membrane of the postsynaptic cell did not change the amplitude of the spikelet; however, on stronger hyperpolarization, the spikelet failed to appear, as previously reported (Vivar et al., 2012). Mixed electrical-chemical activity appeared spontaneously and after MF stimulation (Fig. $4 E$ ) in 6 of 50 cells with TMAi at $100 \mu \mathrm{M}$, in 5 of 31 with TMAi at $1 \mathrm{~mm}$, and in 7 of 27 with TMAi at $100 \mathrm{~mm}$. Mefloquine blocked spikelets in three of eight cells after $40 \mathrm{~min}$ of perfusion (Fig. 4F), and in one after adding carbenoxolone. The plot of the cumulative incidence of spikelets is evidence of activation of the silent electrical communication by TMAi with time (Fig. 4G). We obtained the ratio of all synaptic events driving action potentials and the total of synaptic events, and observed that it was augmented from $0.15 \pm 0.11 \quad(n=5)$ in control recordings to $0.33 \pm 0.12(n=6)$ in recordings conducted with TMAi. For comparison, the probability of spontaneous spikelets driving action potentials in cultured pairs recorded with TMAi (50-200 $\mu \mathrm{M})$ and acidic $\mathrm{pH}$ was $0.13 \pm 0.006(n=37)$, whereas none was observed in control recordings.

We were able to retrieve three dye-coupled MFs and pyramidal cells, and reconstructed their trajectory from CA3 to the hilar region (Fig. $5 A$ ). In this figure, although a single pyramidal cell was injected, a contiguous pyramidal cell was also labeled. Despite the difficulty of observing a dye-coupled MF, we could obtain a clearly labeled MF with several giant boutons that we could follow into the hilar region, close to the GC layer. Additionally, despite the estimation of electrical connections 
A

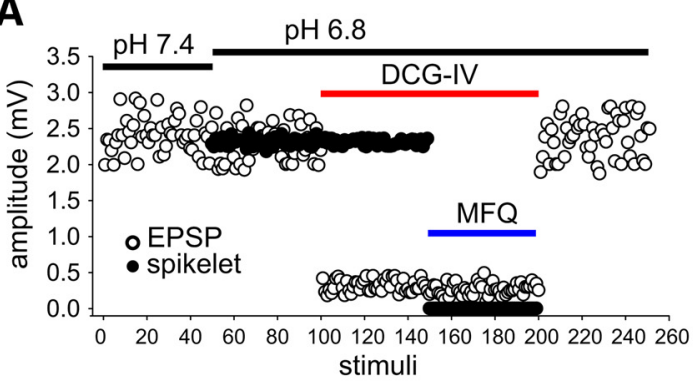

C

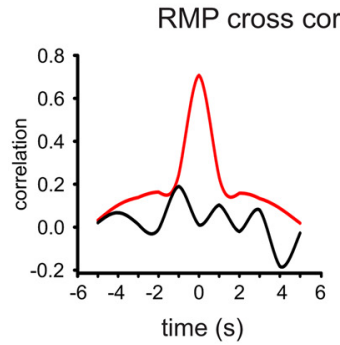

$\mathbf{F}$
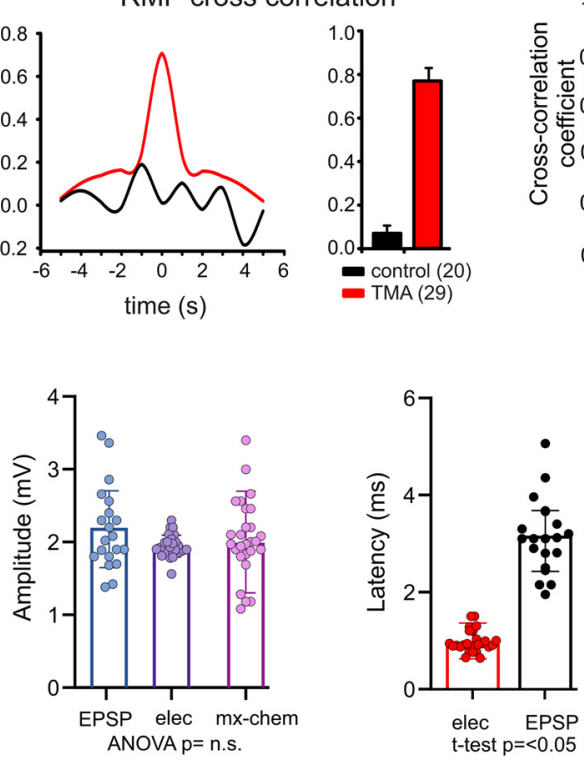

D

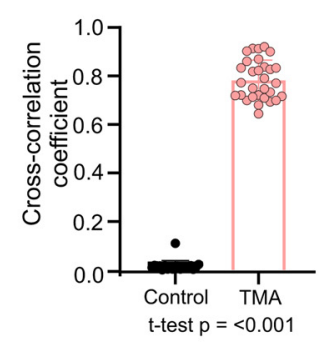

B

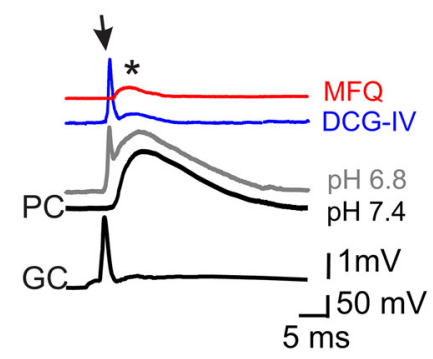

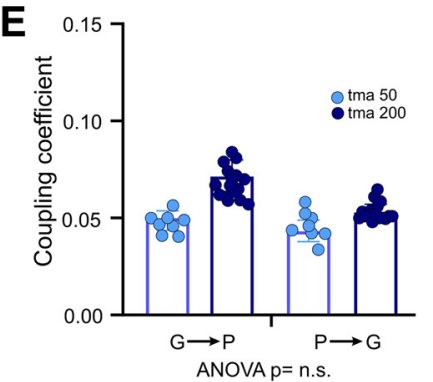
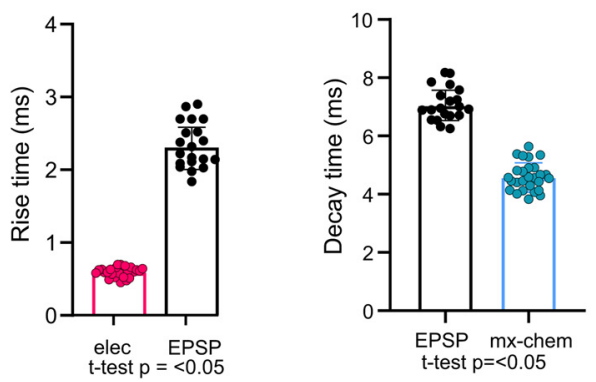

Figure 3. Silent, bidirectional electrical connections are modulated by pH. $A$, Responses of a pyramidal cell (PC) to the action potentials of a $\mathrm{GC}$ in normal pH 7.4 condition (black trace) and acidic ACSF pH 6.8 condition (gray trace). B, The EPSPs (asterisk) were depressed by DCG-IV (blue trace), while spikelets (arrow) were blocked by mefloquine (MFQ; red trace). C, The cross-correlation of the resting membrane potential (RMP) of two cells in a pair recorded with TMAi (left) showed that they synchronize along the experiment (red line), whereas the RMP of uncoupled pairs showed no correlation (black line). $\boldsymbol{D}$, Correlation coefficient of the RMP of the presynaptic and postsynaptic cells in the whole set of control and TMA-containing experiments. $\boldsymbol{E}$, Cross-correlation of RMPs in pairs without TMAi (control) and with TMAi. $G \rightarrow P$, Granule cell to pyramidal cell current transmission; $P \rightarrow G$, pyramidal cell to granule cell current transmission. $F$, Bar plots depicting the values (mean \pm SEM) of the different parameters obtained from the different synaptic events: EPSP, EPSP alone; mx-chem, chemical component of the mixed response; elec, electrical component.

between pyramidal cells being extremely rare (Guzman et al., 2016), we saw 2-5 dye-coupled neighboring pyramidal cells to 12 pyramidal cells recorded with TMAi (Fig. $5 B$ ). Interestingly, we never found evidence of dye-coupled interneurons, despite having filled extensive regions of the dendritic arbor of the pyramidal cells.

\section{Silent but ready-to-use MF electrical synapses in CA3 pyramidal cells revealed in vivo}

To corroborate that silent electrical synapses may be detected in vivo, we intracellularly recorded pyramidal cells without and with TMAi $(1 \mathrm{~mm})$ in the temporal CA3 region of urethaneanesthetized adult rats. None of the 11 control recordings presented spontaneous spikelets. In pyramidal cells recorded with TMAi, activity initially was indistinguishable from the control experiments (Fig. 6A1,A2); however, in 8 of 11 cells, spikelets and mixed spikelet-EPSPs appeared after a median of $25 \mathrm{~min}$ (range, 19-27 min) of impaling the cells (Fig. 6B1-C, Table 1). The proportion of cells affected by TMAi as well as the cumulative incidence of synaptic activity consistent with axo-dendritic mixed synapses (Fig. 6D) reveal the activation of silent gap junctions. Importantly, the probability of spontaneous spikelets eliciting action potentials was $0.23 \pm 0.03$ (Fig. $6 E$ ). We were able to observe dyed-coupled MFs, one along the stratum lucidum and other in the hilar region, after injecting pyramidal cells in two preparations. Figure $5 C$ depicts a labeled pyramidal cell in the proximal area of CA3 and two segments of a dye-coupled MF along the stratum lucidum, where giant MFs were apparent.

\section{Turning on a silent DG-CA3 electrical network}

Finally, to assess whether opening electrical connections in the MF synapse produced coactivation of groups of granule cells and pyramidal cells, we recorded extracellular activity from slices with an array of microelectrodes (3Brain) in the presence of iGluR and iGABAR blockers at physiological pH 7.3 and acidic $\mathrm{pH}$ 6.8. Each action potential of all granule cells was correlated with all action potentials of pyramidal cells that appeared within a 2-6 ms window, followed by a Monte Carlo test (see Materials and Methods) to determine coactivation (Fig. $7 A-C$ ). The results illustrated in Figure 7 were obtained from a total of 367 granule cells and 1934 pyramidal cells of CA3. At physiological pH, 16 of 367 granule cells formed coactive pairs with 46 of 1934 
pyramidal cells, making a total of 72 interactions between them (Fig. 7D1). On perfusion of ACSF with $\mathrm{pH} 6.8$, there were 23 of 367 granular coactive granule cells and 74 of 1934 coactive pyramidal cells. The total interactions established at acidic $\mathrm{pH}$ was 154, representing a $113 \%$ increase in the total number of pairs detected with respect to normal pH (Fig. 7D2). In the presence of the mefloquine, we found 7 of 367 coactive granule cells and 10 of 1934 coactive pyramidal cells. The total number of interactions detected in this condition was 12 , which represents an $83.3 \%$ drop of the detectable coactive pairs (Fig. 7D3). This trend was observed in three experiments. We next determined the number of action potentials of granule cells that generated an action potential in pyramidal cells divided by the total number of action potentials of the granule cell (Fig. 7E3). As expected, acidic $\mathrm{pH}$ increased not only the interactions but also the efficiency (Fig. 7E1-F2), and mefloquine was able to block this effect (Fig. 7G1,G2). Figure 7, E3, F3, and G3, depicts the relation between efficiency and the number of events of coactivation. It is noteworthy that the number of functional electrical connections that we detect is strongly underestimated because most electrical transmissions would be below threshold for extracellular detection (Fig. 7E1,E2).

\section{Discussion}

Our findings show for the first time the broad expression of gap junctions, in a silent state, in one of the most studied glutamatergic synapses, the MF synapse. Our surprising discovery that intracellular, but not extracellular, exposition of the granule or pyramidal cells to TMA resulted in profuse dye coupling of cultured cells suggested that the synapses were normally present but closed. Indeed, TMAi activated silent electrical connections in the recorded cells constituted an invaluable tool to probe for and demonstrate their presence. Thus, with systematic electrophysiological experiments, we could show that TMAi revealed an electric conductance in a synaptic-selective manner in cultured cell pairs, slices (at cellular and circuit levels), and in vivo. The hypothesis that only few pyramidal cells of CA3 responded with electrical spikelets on
A1
TMAi 1 min; normal ACSF

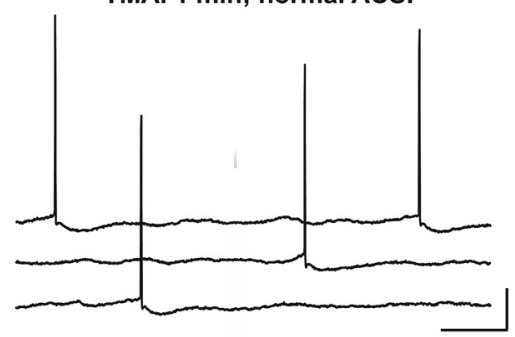

B1

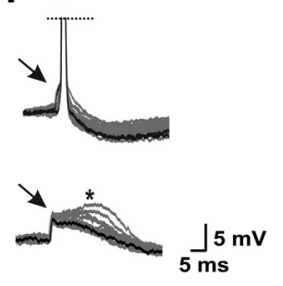

C1

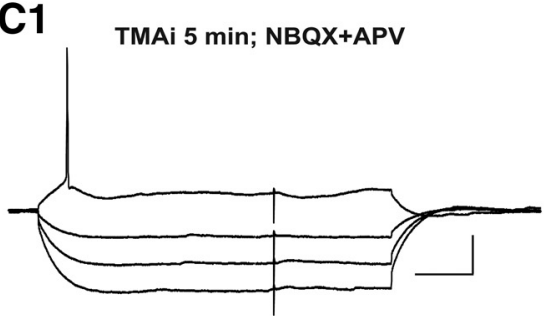

D
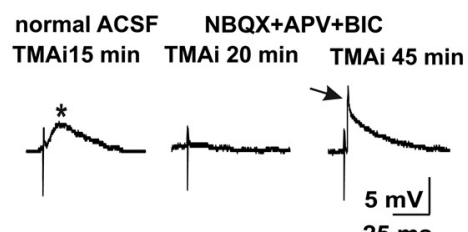

$\mathbf{F}$

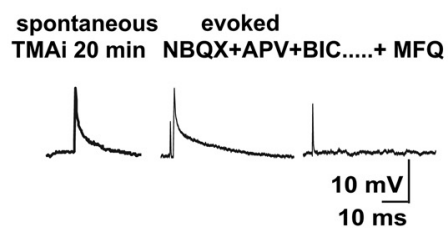

A2

TMAi 20 min; normal ACSF

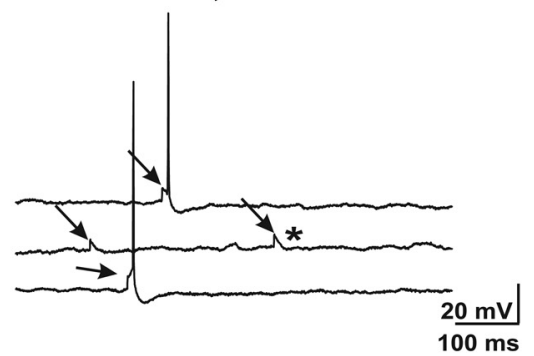

B2

$\mathrm{dV} / \mathrm{dt}$
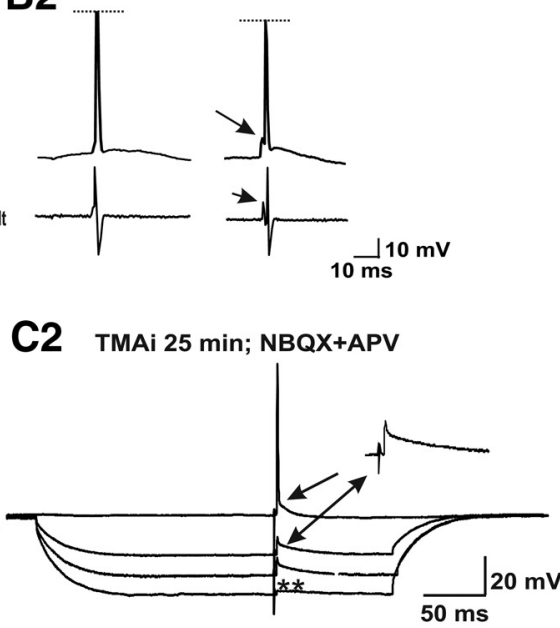

E TMAi 20 min
spontaneous evoked

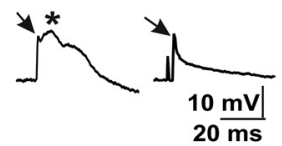

G

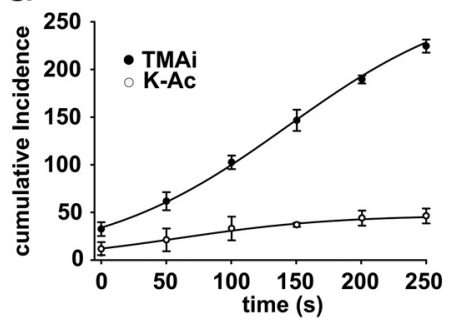

C2 TMAi 25 min; NBQX+APV

Figure 4. Silent but ready-to-use electrical synapses in the mossy fibers revealed in acute slices. A1, Spontaneous recording of a pyramidal cell (PC) a minute after stabilizing the recorded cell using a microelectrode containing TMA. A2, Strikingly, after 20 min of recording, mixed electrical-chemical synaptic activity appeared in cells recorded with TMAi. Arrows signal the electrical spikelets, and asterisks signal the chemical EPSP. B1, Superposition of action potentials and mixed electrical-chemical EPSPs acquired once the effect of TMAi revealed the electrical component. $\mathbf{B 2}$, Action potentials and their derivatives before and after the effect of TMAi; when a shoulder potential gave rise to an action potential, the dotted lines show that the action potentials were cropped. C1, Voltage responses to intracellular current injection in the presence of iGluR antagonists. Chemical synaptic responses to MF stimulation were blocked 5 min after impaling the cell with a microelectrode containing TMA. (2), The cell depicted in $\mathbf{C}$ responded with electrical spikelets after $25 \mathrm{~min}$ of recording with TMAi. The amplitude of the spikelet did not change at different membrane potentials (bidirectional arrow); however, it was prevented from changing during strong hyperpolarization (asterisks). Arrows signal an action potential evoked at RMP. D, A few minutes after impaling the cell with a microelectrode containing TMA, MF stimulation normally produces an EPSP in the PC that can be blocked by iGluR antagonist. After a variable time, a fast spikelet was evoked, revealing a previously silent electrical synapse. $\boldsymbol{E}$, If recordings with TMAi are conducted under normal neurotransmission conditions, mixed EPSPs appear over time and the spikelet could be isolated in the presence of iGluR antagonists. $\boldsymbol{F}$, Spontaneous and evoked spikelets could be blocked by MFQ. $\mathbf{G}$, Cumulative incidence of spikelets during intracellular recordings with electrodes containing K-Ac alone $(n=5)$ or with TMA $(n=6)$. Notice that spikelets normally appeared in control recordings and that TMAi produced a steep increase in the cumulative incidence. Time 0 in the plot was fixed to the moment where a change in the slope of the cumulative incidence was observed in TMAi. 
Table 1. Characteristics of the electrical and chemical components of the mixed synapses between MF and pyramidal cells

\begin{tabular}{|c|c|c|c|c|c|c|c|}
\hline Characteristics & $\begin{array}{l}\text { Spikelets in GC-PC } \\
\text { pairs in culture } \\
\text { with TMAi } \\
\text { ( } n=27 \text { pairs) }\end{array}$ & $\begin{array}{l}\text { Spontaneous spikelets } \\
\text { in PCs with TMAi } \\
\text { recorded in slices } \\
(n=18)\end{array}$ & $\begin{array}{l}\text { Evoked spikelets } \\
\text { in PCs with TMAi } \\
\text { recorded in slices } \\
(n=8)\end{array}$ & $\begin{array}{l}\text { Glutamatergic } \\
\text { component cultures } \\
\text { ( } n=7 \text { pairs) }\end{array}$ & $\begin{array}{l}\text { Glutamatergic } \\
\text { component } \\
\text { slices }\end{array}$ & $\begin{array}{l}\text { Spikelets in PCS } \\
\text { with TMAi } \\
\text { recorded in vivo } \\
(n=8)\end{array}$ & $\begin{array}{l}\text { Glutamatergic } \\
\text { component } \\
\text { in vivo } \\
\text { ( } n=8 \text { cells })\end{array}$ \\
\hline Amplitude & $\begin{array}{l}1.9 \pm 0.2 \mathrm{mV} \\
{[1.79-2.00]}\end{array}$ & $\begin{array}{l}2.79 \pm 1.3 \mathrm{mV} \\
{[0.24-5.34]}\end{array}$ & $\begin{array}{l}18.4 \pm 6.5 \mathrm{mV} \\
{[5.66-31.4]}\end{array}$ & $\begin{array}{l}1.9 \pm 0.9 \mathrm{mV} \\
{[1.04-2.75]}\end{array}$ & $\begin{array}{l}3.8 \pm 0.2 \mathrm{mV} \\
{[3.4-4.2]}\end{array}$ & $\begin{array}{l}6.4 \pm 0.5 \mathrm{mV} \\
{[5.52-7.28]}\end{array}$ & $\begin{array}{l}7.2 \pm 0.5 \mathrm{mV} \\
{[5.36-9.04]}\end{array}$ \\
\hline Decay time & $\begin{array}{l}1.8 \pm 0.1 \mathrm{~ms} \\
{[1.21-2.39]}\end{array}$ & $\begin{array}{l}1.5+0.01 \mathrm{~ms} \\
{[1.48-1.52]}\end{array}$ & $\begin{array}{l}1.8+0.1 \mathrm{~ms} \\
{[1.6-2.0]}\end{array}$ & $\begin{array}{l}4.4 \pm 0.4 \mathrm{~ms} \\
{[3.45-5.34]}\end{array}$ & $\begin{array}{l}18.8 \pm 0.2 \mathrm{~ms} \\
{[18.4-19.2]}\end{array}$ & $\begin{array}{l}2.7 \pm 0.1 \mathrm{~ms} \\
{[2.08-3.31]}\end{array}$ & \\
\hline
\end{tabular}

Values are expressed as the mean \pm SEM $[95 \% \mathrm{CI}]$.

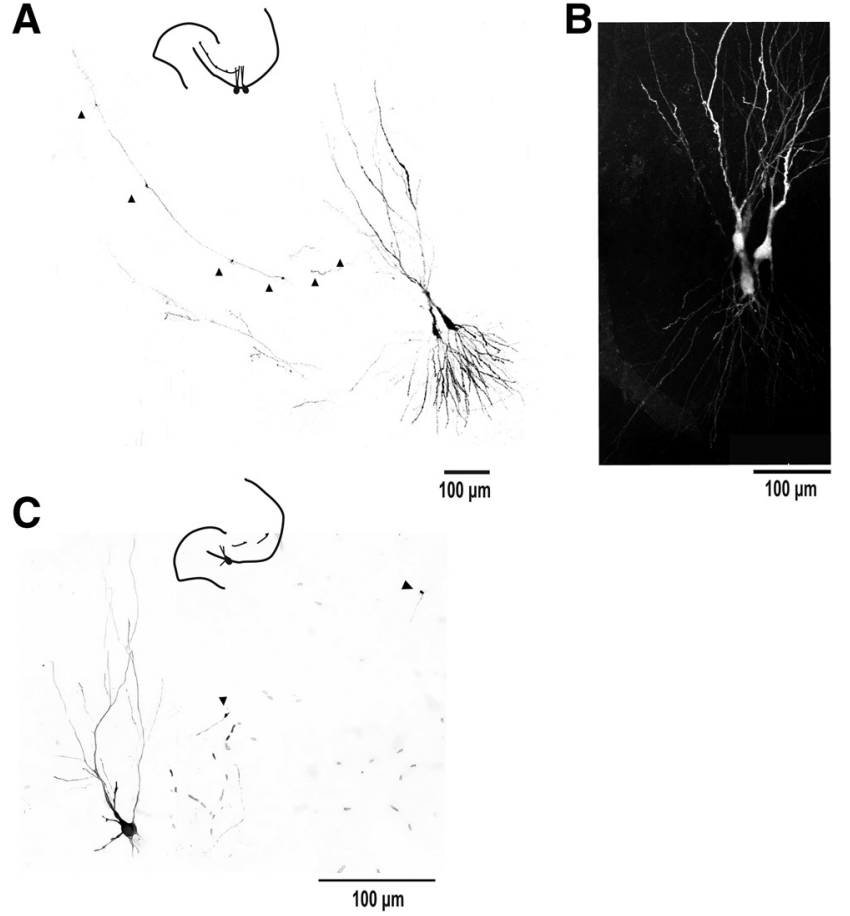

Figure 5. Dye coupling of pyramidal cells (PCS) and mossy fibers in slices. $A$, Two dyecoupled PCs and a long MF, which could be traced from CA3 into the hilus. Arrowheads signal giant MF boutons. Inset depicts the approximate localization of the PC and MF in the slice. $\boldsymbol{B}$, Dye coupling of four PCs after recording one with TMAi. In this case, only a portion of the MF could be observed far from the cells. These photomicrographs contain embedded augmented reality elements depicting a 3D reconstruction and a video. Download the B-Card app for mobile devices and focus the images through the camera in the device. C, A PC labeled in vivo. It was dye coupled to a long, partially recovered MF containing giant boutons (arrows), which could be traced from CA3 toward CA2. Arrowheads signal giant MF boutons. Inset depicts the approximate localization of the PC and MF in the slice.

MF stimulation (Vivar et al., 2012) because the connections are silent was suggested by the abundant presence of $\mathrm{Cx} 36$ along the stratum lucidum of CA3 (Nagy, 2012). To conduct paired recordings and determine the nature and characteristics of neurotransmission, we used especially designed cell cultures (Osorio et al., 2013). We showed that virtually all granule and pyramidal cells express the machinery supporting electrical communication, that it is normally silent, and that we could activate on demand. Although conducting paired recordings in slices is extremely difficult, we could show in pyramidal cells, which initially received exclusively chemical transmission from the MFs, that intracellularly recording with TMA in the microelectrode slowly leaked TMA, which led to the activation of electrical transmission on MF stimulation in the recorded cell. Importantly, using this method, we also show that electrical synapses also actuate in vivo. Activation of electrical connections produces mixed synaptic events that are characterized by an initial fast component (electrical spikelet) followed by a slower glutamatergic component. Indeed, the waveform of the synaptic events allows a clear distinction between chemical EPSPs, standalone spikelets (likely originated between axons or dendrites), and spikelets-plus-EPSPs that can only be originated in axo-dendritic synapses containing gap junctions and glutamate receptors, as the MFs do (Hamzei-Sichani et al., 2012; Nagy, 2012).

Contrary to the notion that $\mathrm{Cx} 36$ is transiently increased during postnatal development followed by its elimination from adult hippocampus (Belousov and Fontes, 2013; Pereda, 2014), our results show that gap junctions are present, but mainly closed, in the adult rodent. At this point, it would be speculative to suggest why only a very small proportion $(<10 \%)$ of mixed synapses can be detected with intracellular recordings in slices, under control conditions. The conditions of their opening by acidic $\mathrm{pH}$ are unknown as well, as changes of $\mathrm{pH}$ in the synaptic microenvironment can be produced by several routes (Ruusuvuori and Kaila, 2014). Having recognized this new property of the MF synapse will allow us to design and conduct experiments that can resolve these questions. Interestingly, all pairs in the cultures presented electrical communication on TMAi action, which demonstrated that all have silent gap junctions. The presence of spontaneous spikelets in cultured cells, which only appeared with TMAi, point to the presence of axo-axonic and dendro-dendritic electrical synapses, in addition to the presence of mixed synapses. Interestingly, far more spikelets and mixed synaptic events were observed in slices than in vivo, which strongly suggests that the cutting procedure facilitates ephaptic or electrical communication. Indeed, it has been shown that high-frequency activity recorded in the slices may result from activation of electrical synapses in axonal plexus (for review, see Traub et al., 2018). Evidence for the presence of spikelets in pyramidal cells in vivo has been related to electrical connectivity between pyramidal cells in CA1 (Epsztein et al., 2010) and, in vitro, to axo-axonal connectivity (Schmitz et al., 2001; Traub et al., 2012).

Although CA3 pyramidal cells have a high connectivity, and they can contain gap junctions, we here demonstrate that input from principal cells located out of the CA3 region, in the dentate gyrus, may have a finer control of CA3 pyramidal cells by the existence of gap junctions that may be activated by changes in $\mathrm{pH}$. Although our goal was to prove the existence of such a network, which we did, we can speculate that different $\mathrm{CO}_{2}$ blood levels due to changes in oxygenation conditions as well as pathologic states that can change $\mathrm{pH}$ may regulate the activation or 


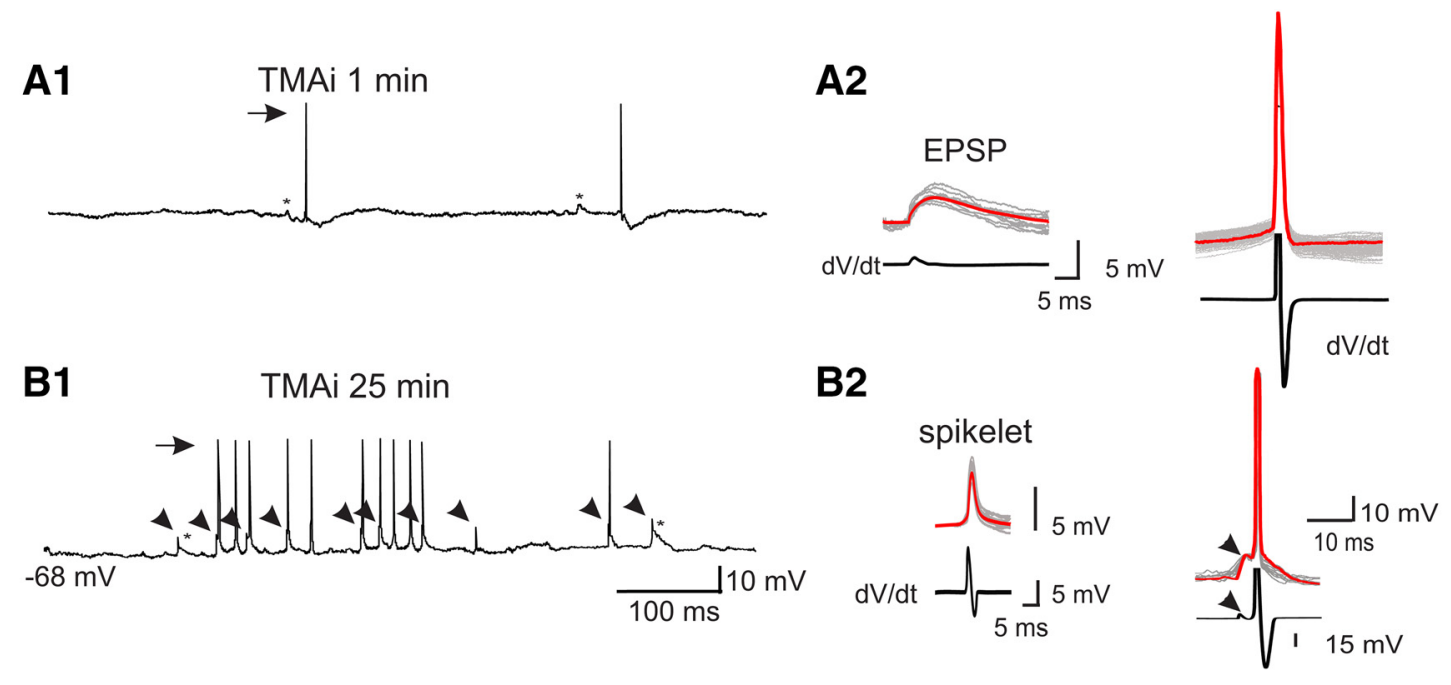

C

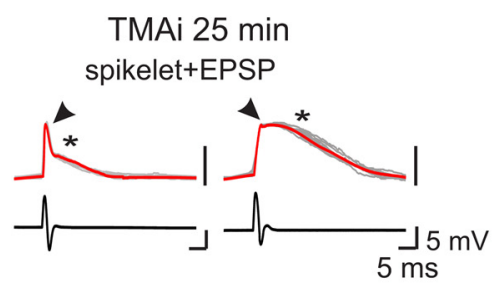

D

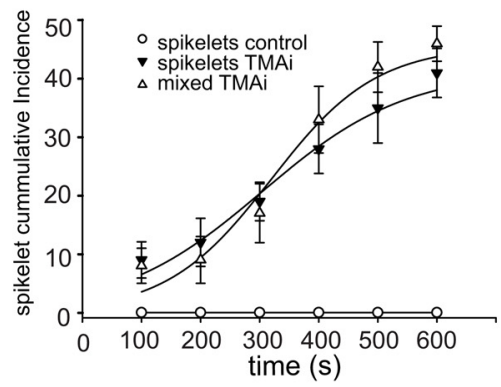

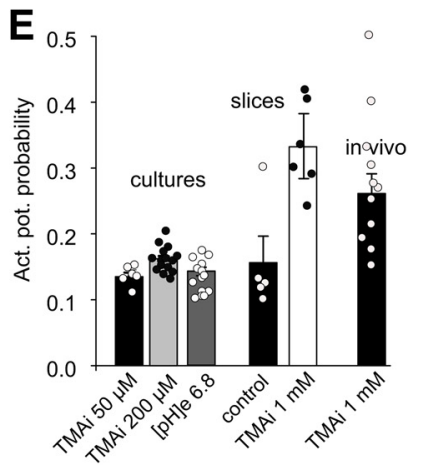

Figure 6. Silent but ready-to-use MF electrical synapses in CA3 pyramidal cells revealed in vivo. A1, Intracellular recording of a pyramidal cell (PC) in the CA3 region of the ventral hippocampus of an anesthetized rat. The trace is a representative example of recordings conducted with and without TMA in the pipette, some minutes after stabilization of the recording. $\boldsymbol{B 1}$, After 2040 min of recording with microelectrodes containing TMA (TMAi), in 8 of 11 PCs we observed a significant increase of electrical synaptic events. A2, Spontaneous EPSPs and action potentials during the first minutes after impaling. Gray traces are single events, red traces are their average. $\mathbf{B 2}$, After 25 min of recording, electric spikelets and action potentials preceded by spikelets appeared. Gray traces are single events, red traces are their average. Their fast onset could be detected with the derivative of the signals. These may originate from dendro-dendritic or axoaxonic gap junctions. C, By contrast, the mixed electrical-chemical EPSPs that appeared with time are likely to originate from axo-dendritic synapses, where glutamate receptors and gap junctions coexist. Gray traces are single events, red traces are their average. The fast onset of the spikelet could be detected by the derivative. D, Plot depicting the cumulative incidence of electrical synaptic events in PCs in the different conditions (mean \pm SEM). PCs recorded in control condition ( $n=11)$ did not have fast-onset synaptic events (white circles), whereas in those recorded with TMAi, spikelets (black triangles) and mixed events (white triangles) were augmented with time $(n=6)$. Because the onset time of the spontaneous electrical activity differed in the cells (see Results), to observe the trend of spikelet incidence in each group of events, the time 0 in the plot was fixed to the moment where a change in slope of the cumulative incidence was observed in each recording. $\boldsymbol{E}$, Probability of spikelets originating full-blown action potentials in cultures, slices, and in vivo (mean \pm SEM). Note that using TMAi in slices (control, $n=5$; TMAi, $n=6$ ) and in vivo (control, $n=11 ; \mathrm{TMAi}, n=8$ ) strongly enhanced the probability of spikelets preceding action potentials.

deactivation of the electrical component of the MF synapses (Ruusuvuori and Kaila, 2014).

The combined probability of electrophysiologically finding chemical synapses and mixed synapses of MFs with individual pyramidal cells on granule cell activation is $<0.0005$ (Amaral et al., 1990; Jonas et al., 1993; Vivar et al., 2012). Importantly, using TMAi, we found MF-activated mixed synapses with a very high probability in slices $(\sim 20 \%)$ and mixed synapse events in vivo (in 8 of 11 cells). Despite finding this high proportion of cells with mixed synaptic events when using TMAi or low $\mathrm{pH}$, the number is strongly underestimated, considering that many microelectrodes may have not leaked (enough) TMA (both in slices and in vivo) or that field stimulation did not recruit an MF coupled to a pyramidal cell, in the slices, where pyramidal cells are strongly deafferented.

The coupling force values that we obtained with our paired recordings are similar to those previously reported in neocortical interneurons (Amitai et al., 2002) and inferior olivary neurons (Hoge et al., 2011). We found that the ratio of action potentials/ synaptic events showed an increase when spikelets are present, which may be due to summation of the synaptic components (Vivar et al., 2012). This property has never been observed before due to the quiescent state of the electrical synapse under baseline conditions. Thus, the "mixed synapse" nature of MF boutons has important functional implications for synaptic plasticity. Indeed, we found that electrical signaling may constitute a safety factor, which could be of particular importance for synapses with low release probability (Jonas et al., 1993). In Caenorhabditis elegans, a rectifying electrical synapse (which transmits from the post synaptic to the presynaptic terminal) coexisting with a chemical synapse, potentiates neurotransmitter release (Liu et al., 2017). We show with paired recordings that the resting membrane potential can be transmitted bidirectionally, and this possibly modulates the probability of action potential transmission in situ. We and others (Schmitz et al., 2001; Vivar et al., 2012) have observed that strong hyperpolarization of the postsynaptic cell prevents the electrical spikelet to appear on input stimulation, although the underlying mechanism has not been fully disclosed. 
A

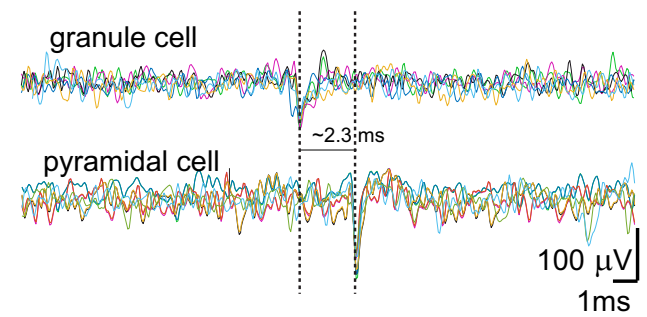

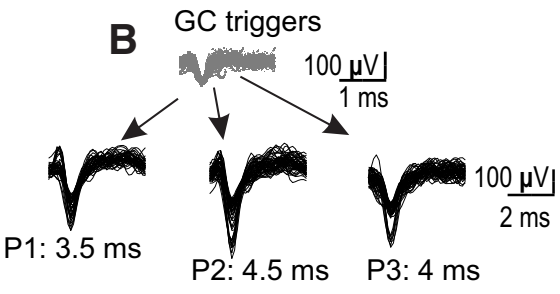

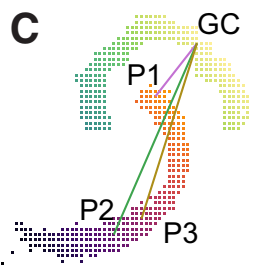

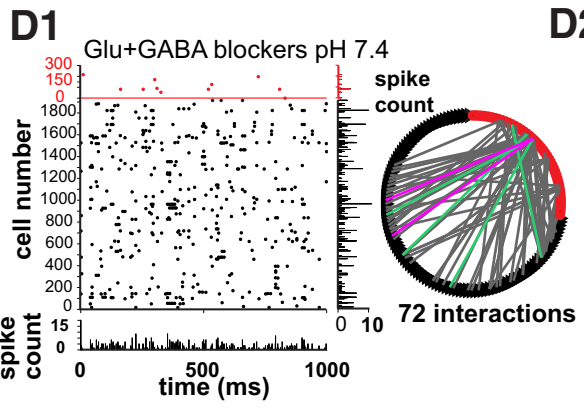

E1
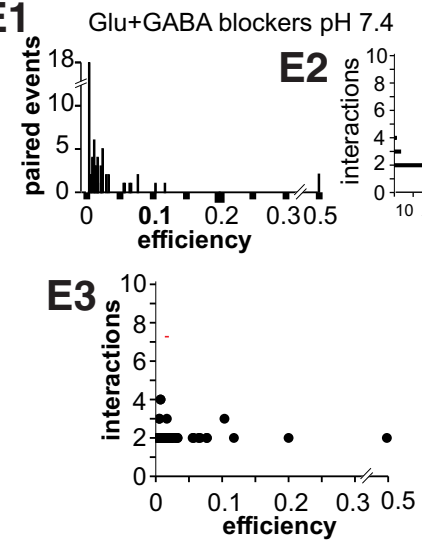

D2

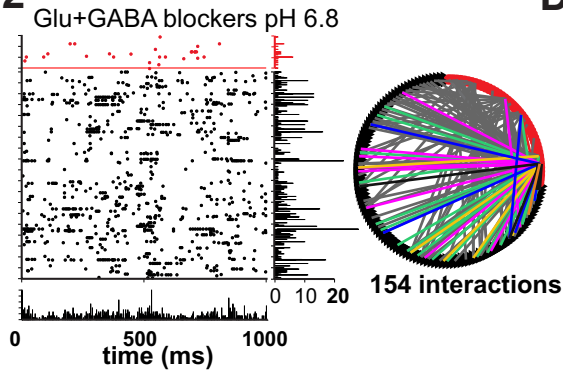

F1

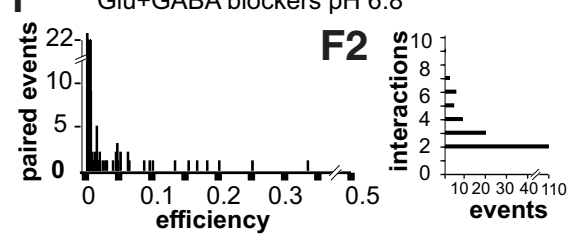

F3

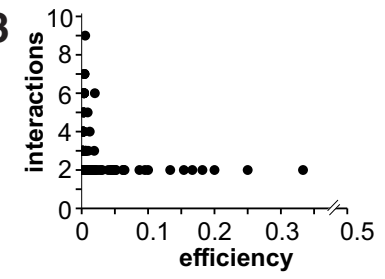

D3

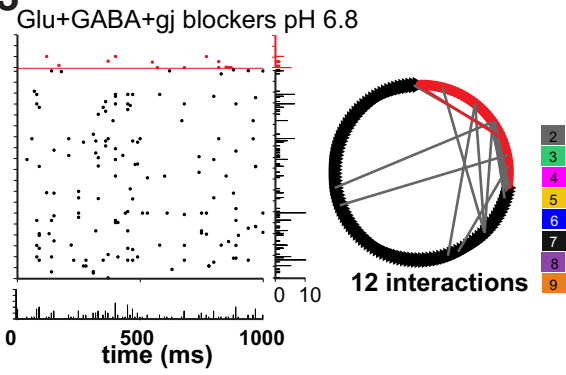

G1 Glu+GABA+gj blockers pH 6.8
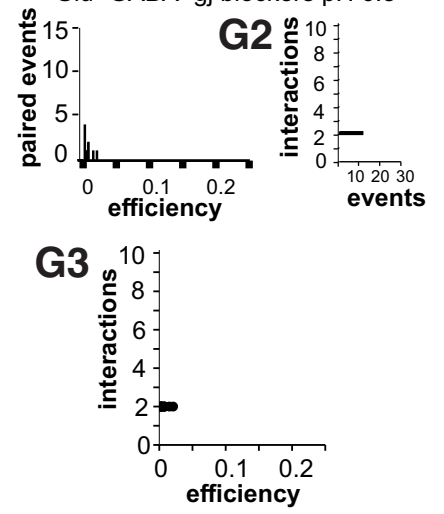

Figure 7. Turning on a silent $\mathrm{DG}-\mathrm{CA} 3$ electrical network. $A$, Raw traces obtained from two channels recording a $\mathrm{GC}$ and a pyramidal cell (PC), which consistently fired with a $2.3 \mathrm{~ms}$ latency. Time-locked events like these were searched for each GC against all PCs detected. $\boldsymbol{B}$, Single GCs could drive more than one PC. The GC triggered 71 events in P1 at a distance of $270 \mu \mathrm{m} ; 51$ events in P2 at a distance of $804 \mu \mathrm{m}$; and 45 events at a distance of $746 \mu \mathrm{m}$. C, Position of the GC and PCs depicted in B. D1-D3, Raster plots of a $1 \mathrm{~s}$ sample of spontaneous activity of 367 GCs (red dots) and 1934 PCs (black dots) recorded during 5 min of each experimental condition, and histograms depicting event count for each 1 ms time bin (below) and for each cell (on the right) in control pH (D1), acidic pH (D2), and acidic pH plus mefloquine (D3). Notice that acidic pH provoked an increase in the number of action potentials as well as in the number of interactions, which are depicted in the color circles. The color of the lines represents the number of coactive events of the linked cells, represented by red circles (GCS) and black triangles (PCs). Mefloquine antagonized the effect of acidic pH. Right, Color scale used in the lines showing the number of coactive events for each color. E1, Plot depicting the efficiency of the connections under iGluR and iGABA $A-R$ blockers at physiological pH during $5 \mathrm{~min}$. E2, Histogram of the number of coactivated pairs that had $n$ occurrences. E3, Plot depicting the relation of E1 with E2, whereby ordinates show the number of interactions that appeared with a given efficiency (abscissae). F1-F3, The same analyses shown in E1 and E2, in acidic ACSF, and in G1-G3 in acidic ACSF plus mefloquine.

Our paired recordings show bidirectional electrical transmission, suggesting the possibility that the presynaptic bouton can be hyperpolarized and thus shunt the action potential and, possibly, further convey antidromic analog subthreshold signaling (Alle and Geiger, 2006). This hypothesis will have to be explored either with direct electrophysiological recordings of the presynaptic boutons or with voltage-sensitive dyes.

$\mathrm{pH}$ shifts have strong effects on neuronal excitability and, importantly, on synaptic transmission. Synaptic transmission per se produces $\mathrm{pH}$ changes as well. In a synapse where silent but activatable electrical transmission coexists with chemical transmission, $\mathrm{pH}$ shifts may regulate its activation and deactivation and not only neurotransmitter loading (Sinning and Hübner, 2013). Just like synaptic activity produces $\mathrm{pH}$ gradients, largerscale events like epilepsy, anoxia, and stroke produce shifts of $\mathrm{pH}$ in a broader area that, in turn, impact on synaptic transmission and, most likely, in opening and closing of gap junctions that are sensitive to such changes (González-Nieto et al., 2008; Sinning and Hübner, 2013). Moreover, this pathologic activity induces an upregulation in the expression of gap junctions (Belousov and Fontes, 2013). It is possible that events that impact all regulatory molecules of cellular $\mathrm{pH}$, namely, $\mathrm{Ca}^{2+} / \mathrm{H}^{+}$-ATPase, carbonic anhydrases, acid-sensing ion channels, and GABAR-mediated bicarbonate efflux, modulate gap junction opening by causing microenvironmental $\mathrm{pH}$ active changes (Ruffin et al., 2014).

In all, this is an intriguing and complex question, and we could now list endless possibilities in which activity, $\mathrm{PCO}_{2}$ and $\mathrm{H}^{+}$fluxes might interact in a functional brain to trigger the opening of gap junctions. Importantly, this opens the possibility of concerted, locked rhythmogenesis of hippocampal substructures via their principal cells and not only via local interneuronal synchronization. Opening granule cell-to-pyramidal cell electrical connections may broaden the constitutive elements of a given neuronal network and oscillations may thus be supported by resonance provided by electrical connections (Coulon and Landisman, 2017; Traub et al., 2018). Optimization of nodes in 
such a network may be a function of activity, either physiological or pathologic (Pereda, 2014). Knowing the presence of silent gap junctions in a glutamatergic synapse and that they can be activated will enable us to disclose their functions. It is likely that this type of connection is present in other structures of the CNS, underlying unexplored computational and regulatory mechanisms.

\section{References}

Alle H, Geiger JR (2006) Combined analog and action potential coding in hippocampal mossy fibers. Science 311:1290-1293.

Amaral DG, Ishizuka N, Claiborne B (1990) Neurons, numbers and the hippocampal network. Prog Brain Res 83:1-11.

Amitai Y, Gibson JR, Beierlein M, Patrick SL, Ho AM, Connors BW, Golomb D (2002) The spatial dimensions of electrically coupled networks of interneurons in the neocortex. J Neurosci 22:4142-4152.

Belousov AB, Fontes JD (2013) Neuronal gap junctions: making and breaking connections during development and injury. Trends Neurosci $36: 227-236$

Bezanson J, Edelman A, Karpinski S, Shah VB (2017) Julia: a fresh approach to numerical computing. SIAM Rev 59:65-98.

Coulon P, Landisman CE (2017) The potential role of gap junctional plasticity in the regulation of state. Neuron 93:1275-1295.

Cruikshank SJ, Hopperstad M, Younger M, Connors BW, Spray DC, Srinivas M (2004) Potent block of Cx36 and Cx50 gap junction channels by mefloquine. Proc Natl Acad Sci U S A 101:12364-12369.

Epsztein J, Lee AK, Chorev E, Brecht M (2010) Impact of spikelets on hippocampal CA1 pyramidal cell activity during spatial exploration. Science 327:474-477.

Galarreta M, Hestrin S (2001) Electrical synapses between GABA-releasing interneurons. Nat Rev Neurosci 2:425-433.

Gibson JR, Beierlein M, Connors BW (1999) Two networks of electrically coupled inhibitory neurons in neocortex. Nature 402:75-79.

González-Nieto D, Gómez-Hernández JM, Larrosa B, Gutiérrez C, Muñoz MD, Fasciani I, O’Brien J, Zappalà A, Cicirata F, Barrio LC (2008) Regulation of neuronal connexin-36 channels by pH. Proc Natl Acad Sci U S A 105:17169-17174.

Guzman SJ, Schlögl A, Frotscher M, Jonas P (2016) Synaptic mechanisms of pattern completion in the hippocampal CA3 network. Science 353:11171123.

Hamzei-Sichani F, Kamasawa N, Janssen WG, Yasumura T, Davidson KG, Hof PR, Wearne SL, Stewart MG, Young SR, Whittington MA, Rash JE, Traub RD (2007) Gap junctions on hippocampal mossy fiber axons demonstrated by thin-section electron microscopy and freeze fracture replica immunogold labeling. Proc Natl Acad Sci U S A 104:12548-12553.

Hamzei-Sichani F, Davidson KG, Yasumura T, Janssen WG, Wearne SL, Hof PR, Traub RD, Gutiérrez R, Ottersen OP, Rash JE (2012) Mixed electrical-chemical synapses in adult rat hippocampus are primarily glutamatergic and coupled by connexin-36. Front Neuroanat 6:13.

Hoge GJ, Davidson KG, Yasumura T, Castillo PE, Rash JE, Pereda AE (2011) The extent and strength of electrical coupling between inferior olivary neurons is heterogeneous. J Neurophysiol 105:1089-1101.

Hooper SL, Thuma JB, Guschlbauer C, Schmidt J, Büschges A (2015) Cell dialysis by sharp electrodes can cause nonphysiological changes in neuron properties. J Neurophysiol 114:1255-1271.

Hulata E, Segev R, Ben-Jacob E (2002) A method for spike sorting and detection based on wavelet packets and Shannon's mutual information. J. Neurosci. Methods 117:1-12.

Jonas P, Major G, Sakmann B (1993) Quantal components of unitary EPSCs at the mossy fibre synapse on CA3 pyramidal cells of rat hippocampus. J Physiol 472:615-663.
Liu P, Chen B, Mailler R, Wang ZW (2017) Antidromic-rectifying gap junctions amplify chemical transmission at functionally mixed electricalchemical synapses. Nat Commun 8:14818.

MacVicar BA, Dudek FE (1981) Electrotonic coupling between pyramidal cells: a direct demonstration in rat hippocampal slices. Science 213:782785 .

Nagy JI (2012) Evidence for connexin36 localization at hippocampal mossy fiber terminals suggesting mixed chemical/electrical transmission by granule cells. Brain Res 1487:107-122.

Ortiz F, Zapfe WPK, Draguhn A, Gutiérrez R (2018) Early appearance and spread of fast ripples in the hippocampus in a model of cortical traumatic brain injury. J Neurosci 38:9034-9046.

Osorio B, León U, Galván EJ, Gutiérrez R (2013) Co-cultures of GFP ${ }^{+}$-granule cells with $\mathrm{GFP}^{-}$-pyramidal cells and interneurons for the study of mossy fiber neurotransmission with paired recordings. Hippocampus 23:247-252.

Paxinos G, Watson C (1997) The rat brain in stereotaxic coordinates. San Diego: Academic.

Pereda AE (2014) Electrical synapses and their functional interactions with chemical synapses. Nat Rev Neurosci 15:250-263.

Quiroga RQ, Nadasdy Z, Ben-Shaul Y (2004) Unsupervised spike detection and sorting with wavelets and superparamagnetic clustering. Neural Comput 16:1661-1687.

Ruffin VA, Salameh AI, Boron WF, Parker MD (2014) Intracellular pH regulation by acid-base transporters in mammalian neurons. Front Physiol 5:43.

Ruusuvuori E, Kaila K (2014) Carbonic anhydrases and brain pH in the control of neuronal excitability. In: Carbonic anhydrase: mechanism, regulation, links to disease, and industrial applications (Frost SC, McKenna R, eds), pp 271-290. Dordrecht, The Netherlands: Springer.

Schmitz D, Schuchmann S, Fisahn A, Draguhn A, Buhl E, Petrasch-Parwez E, Dermietzel R, Heinemann U, Traub RD (2001) Axo-axonal coupling, a novel mechanism for ultrafast neuronal communication. Neuron 31:831-840

Sinning A, Hübner CA (2013) Minireview: pH and synaptic transmission. FEBS Lett 587:1923-1928.

Skeberdis VA, Rimkute L, Skeberdyte A, Paulauskas N, Bukauskas FF (2011) $\mathrm{pH}$-dependent modulation of connexin-based gap junctional uncouplers. J Physiol 589:3495-3506.

Spencer WA, Kandel ER (1961) Electrophysiology of hippocampal neurons: IV. Fast prepotentials. J Neurophysiol 24:272-285.

Thomas RC (1984) Review lecture: experimental displacement of intracellular $\mathrm{pH}$ and the mechanism of its subsequent recovery. J Physiol 354 [Suppl]:3-22.

Traub RD, Schmitz D, Maier N, Whittington MA, Draguhn A (2012) Axonal properties determine somatic firing in a model of in vitro CA1 hippocampal sharp wave/ripples and persistent gamma oscillations. Eur J Neurosci 36:2650-2660

Traub RD, Whittington MA, Draguhn A (2017) Gap junctions between pyramidal cells account for a variety of very fast network oscillations ( $>80$ $\mathrm{Hz}$ ) in cortical structures. In: Network functions and plasticity (Jing J, ed), pp 301-320. Amsterdam: Elsevier/Academic.

Traub RD, Whittington MA, Gutiérrez R, Draguhn A (2018) Electrical coupling between hippocampal neurons: contrasting roles of principal cell gap junctions and interneuron gap junctions. Cell Tissue Res 373:671691.

Valiante TA, Perez-Velazquez JL, Jahromi SS, Carlen PL (1995) Coupling potentials in CA1 neurons during calcium-free-induced field burst activity. J Neurosci 15:6946-6956.

Vivar C, Traub RD, Gutiérrez R (2012) Mixed electrical-chemical transmission between hippocampal mossy fibers and pyramidal cells. Eur J Neurosci 35:76-82. 